\title{
LA FILOSOFÍA DE RORTY Y EL «ESPEJO» DE LA RETÓRICA
}

\author{
JOSÉ A. MARÍN-CASANOVA \\ Universidad de Sevilla
}

\begin{abstract}
RESUMEN: La atención en la obra rortiana a la retórica como tal es mínima, por no decir nula. No hay en Rorty una Filosofía de la Retórica en el sentido objetivo del genitivo. Sin embargo, al romper explícitamente «el espejo de la naturaleza», Rorty está rompiendo implícitamente aquello que posibilitaba el divorcio entre la filosofía y la retórica. De hecho, el propósito de este ensayo es explicitar ese implícito presentando la filosofía rortiana como una Filosofía de la Retórica en el sentido subjetivo del genitivo, es decir, como una Retórica de la Filosofía o una Retórica filosófica.
\end{abstract}

PALABRAS CLAVE: Rorty, Retórica, criterio, persuasión, metáfora.

\section{Rorty's Philosophy and the mirror of Rhetoric}

ABSTRACT: Rhetoric is not a special issue in Rorty's work. In fact, there is not rortian Philosophy of Rhetoric in the objective sense of the genitive. However, when breaking explicitly «the mirror of nature», Rorty is implicitly breaking with the condition that makes possible the divorce between Philosophy and Rhetoric. This article aims to make explicit that implicit matter, and shows Rorty's Philosophy as a Philosophy of Rhetoric in the subjective sense of the genitive, i.e., as a Rhetoric of Philosophy or a Rhetorical Philosophy. KEY WORDS: Rorty, Rhetoric, criterion, persuasion, metaphor.

Our world is a creature and a texture of rhetorics: of founding stories and sales talks, anecdotes and statistics, images and rhythms; of tales told in nursery, pledges of allegiance or revenge, symbols of success and failure, archetypes of action and character. Ours is a world of persuasive definitions, expressive explanations, and institutional narratives. It is replete with figures of truth, models of reality, tropes of argument, and metaphors of conscience. In our world, scholarship is rhetorical.

J. S. Nelson - A. Megill (1986), p. 23.

The pretense of looking at the world directly, as through a one-way screen, seeing others as they really are when only God is looking, is indeed quite widespread. But that is itself a rhetorical strategy, a mode of persuasion; one it may well be difficult wholly to abandon and still be read, or wholly to maintain and still be believed.

C. GeErTZ (1988), p. 141.

¿Era Richard Rorty un filósofo retórico? Para muchos esta pregunta sería una pregunta retórica. Y como tal no merecería ni ser planteada ni ser respondida. De hecho, para sus detractores sería más bien una pregunta absurda por comportar un inaceptable oxímoron. Precisamente por ser retórico ni siquiera sería filósofo. A ello se añadiría además el propio hecho de que Rorty haya abogado en continuo ritornelo por un pensamiento "post-filosófico», con lo cual éste casi vendría a darles la razón a aquéllos. Pero si esto fuera así, Rorty y la filosofía no tendrían nada que decirse mutuamente. Si, sin embargo, se considera que la aportación rortiana al pensamiento contemporáneo ha sido

Este trabajo ha sido realizado dentro del Proyecto de Investigación (I+ D + i) FFI2009-07709 del Ministerio de Educación, Cultura y Deporte. 
worth mentioning, resulta conveniente, por no decir necesario, atender al mencionado oxímoron y tomar en serio la pregunta descalificable como retórica. Ése es el propósito del siguiente estudio. Se trata de mostrar que la retórica es clave de la filosofía rortiana, toda vez que, roto el espejo de la naturaleza, a la filosofía sólo le queda la reflexión en el «espejo» de la retórica; ahora bien, de una retórica redescrita, una Retórica filosófica.

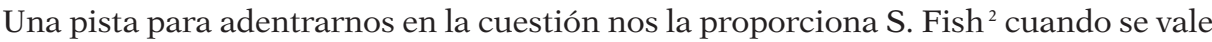
del antagonismo entre el tipo platónico y el tipo sofista para leer la historia del pensamiento occidental. Entre los muchos modos posibles de lectura encuentra que, en efecto, uno de los más interesantes e iluminadores es basarse en la contraposición, diferentemente modulada a lo largo del tiempo, pero siempre recurrente desde los griegos hasta el día presente, entre las posiciones filosóficas fundacionalistas y las retóricas. La querella entre fundacionalismo y retoricismo ha sobrevivido, aún variando históricamente el peso de sus componentes, a todos los maremotos sufridos en nuestra cuenca intelectual. La polémica se ha dado como la sesgada opción entre la verdad plana, presentada sin barnices y directamente, y el «lenguaje fino», de poderoso mas insidioso atractivo, un lenguaje transgresor de los límites de la representación, al sustituir con sus propias formas las formas de la realidad. En esta larga batalla histórica la verdad, encarnada por el "hombre serio", parece haber llevado siempre las de ganar, mientras que la retórica, encarnada por el «hombre retórico», llevaba las de perder. Pero en la actualidad ya no es éste el caso, pues hoy la retórica atraviesa con paso firme y ligero el campo hasta saturar las expresiones culturales. Nuestro mundo se encuentra claramente en «la tenaza de lo retórico», y con ello nos percatamos de que, aun cuando en su largo enfrentamiento con el fundacionalismo el retoricismo no ha resultado manifiestamente exitoso, el conflicto, de hecho, no ha tenido lugar entre dos posiciones en absoluto, sino que ambas posiciones se han desplegado dentro del retoricismo. Así, aunque históricamente el «hombre retórico» no aparezca triunfante sobre el «hombre serio», resulta que este espécimen se revela justo como una construcción retórica: la seriedad no es nada más que otro tropo retórico, la afectación de la que el hombre que la encarna se ayuda para conseguir sus pretensiones. Por ello, para Fish, ahora está claro que el «hombre serio» es un «hombre retórico» y que la retórica era «el único juego en la ciudad».

Una segunda pista introductoria la podemos encontrar en el comentario que redactó H. W. Simons de la Iowa Conference on the Rhetoric of the Human Sciences de 1984. El cronista reconoce que "nadie fue en el congreso más persuasivo que Richard Rorty». Sin embargo, viendo todo lo que tendría que ceder en el camino respecto de la objetividad epistemológica y científica se encontró él mismo «resistiendo el argumento de Rorty de que abandonemos toda epistemología, y con ello, los criterios para distinguir la ciencia de la no-ciencia y el conocimiento certificado de la mera creencia» ${ }^{3}$. Semejante comen-

\footnotetext{
Cf. Fish, S., (1989), pp. 478 ss.; RoRTY, R., (1985), p. 459, dice admirarlo.

Simons, H. W., (1985), p. 58. La referida intervención de Rorty fue «La ciencia como solidaridad» y se recoge en Rorty, R., (1996b), pp. 39-58. Por cierto, Simons pone en circulación la exitosa expresión, aunque él se la atribuye al propio Rorty, de "giro retórico»; en efecto, según Simons, H. W., (1991), p. vii: "En el Iowa Sympsium on The Rhetoric of Human Sciences de 1984, R. Rorty observó que los recientes movimientos para reconcebir la investigación en ciencias humanas parecen estar marcados por "giros".
} 
tario parece expresivo de la (in)comprensión fundacionalista de Rorty que hace de él un mero retoricista. Pero su planteamiento sólo puede catalogarse dentro del retoricismo si desatendemos la recomendación de Fish de considerar el fundacionalismo como movimiento que se desenvuelve dentro del retoricismo, como una variante suya más. Y es que, como vamos a ver, Rorty no está proponiendo ni siquiera implícitamente hacer de lo retórico el nuevo fundamento, el nuevo método del pensamiento. Si así fuera, ciertamente el dilema que plantea Simons sería correcto: habría que escoger entre el conocimiento certificado y la mera creencia. Pero lo que aquí vamos a argumentar es que desde la propuesta rortiana ese dilema no es aceptable. No se trataría de optar a favor de las creencias en detrimento de la objetividad, sino, antes al contrario, de mostrar que tal opción no nos es dada: no hay alternativa a las «meras» creencias.

De hecho, quizá se pueda leer la empresa intelectual rortiana como el intento de «liberar a la humanidad del "más largo error" que Nietzsche desenmascara, la idea de que fuera de nuestros experimentos fortuitos y arriesgados yace algo (Dios, La Ciencia, El Conocimiento, La Racionalidad o La Verdad) que, sólo con seguir los ritos apropiados, acudirá para salvarnos» ${ }^{4}$. En efecto, si asociamos lo propio del espíritu de la gravedad de Nietzsche al «hombre serio» de Fish, la pretensión de Rorty no es otra que la del «hombre retórico». Ciertamente, Rorty apela a Nietzsche para desembarazarnos de la gravedad fundacionalista, de la «mentira» de que tras las apariencias y contingencias cotidianas yazga un Mundo Real, sólido y fundamental, una suerte de realidad perpetua que nos soporte y que nos sea accesible. Ésta sería la fantasía de la tradición occidental de la que Rorty nos quiere desengañar. Pero no para poner en su lugar, por fin, como el Hércules aguardado por las cuadras occidentales, algo verdadero, sino otra fantasía más útil y esperanzadora. Para ello elabora un discurso antifundacional, antirrepresentacional, irónico, conversacional, metafórico y orientado hacia la libertad: un discurso retórico.

Es cierto que Rorty, aunque bastantes veces haya podido referirse a su retórica (o a la de otros, casi nunca a la retórica), jamás ha autocalificado su discurso de «retórico» (como contrapuesto a filosófico). De hecho, la atención rortiana a la retórica como tal es mínima, por no decir nula. No hay en Rorty una Filosofía de la Retórica en el sentido objetivo del genitivo. Sin embargo, como aquí se va a razonar, puede entenderse todo su pensamiento como una Filosofía de la Retórica en el sentido subjetivo del genitivo. La filosofía rortiana es una Retórica de la Filosofía, una Retórica filosófica. Y es que, más allá del que fuera su propósito, la obra rortiana, en general, viene a eliminar los fundamentos de las jerarquías que dicotómicamente separan lo filosófico de lo retórico. Si partimos del hecho de que la filosofía cobra carta de naturaleza desmarcándose de la

Primero el "giro lingüístico", después el "giro interpretativo" y ahora el "giro retórico". Rorty está entre aquellos cuyas críticas de los credos objetivistas han inspirado el nuevo movimiento". Como cabe suponer, el presente artículo no pretende sino aplicar este último aserto a su propio autor y así mostrar el giro retórico del pensamiento rortiano. Por lo demás, Kissel, A., sugiere que Rorty construyó su "giro retórico» a partir de la «revolución retórica» de McKeon — cf. KIssel, A., (2005), p. 8-. Sin embargo, algún autor que podemos considerar afecto a ésta, al poner a la retórica a la base de una nueva forma para la filosofía de nuestro siglo, se muestra crítico con el "giro retórico», en general, y con Rorty, en particular, como es el caso de Oesterreich, P. L., (2002), p. 294, quien responsabiliza a ese giro de «intentar una forma puramente negativa de crítica retórica», a la vista de la cual «se impone la tarea a comienzos del siglo xxI de poner el renacimiento de la retórica en la dirección de una nueva forma positiva y de prolongar la reconstrucción de la filosofía». También ha advertido del peligro del giro retórico rortiano, aunque no desde una perspectiva favorable, sino contraria a la retórica, al menos, de una retórica no sometida a constricciones objetivas, Bragues, G., (2006), p. 180 (sobre los «peligros del proyecto retórico rortiano», por sobreponerse a la lógica y no estar ordenados a la verdad, véase también p. 166).

4 Rorty, R., (1996a), p. 296. 
retórica en tanto que búsqueda de la realidad frente a la eficacia cosmética de la apariencia, todo el esfuerzo intelectual rortiano va dirigido contra semejante desmarque. Hay, en efecto, en el origen de la filosofía un triple dualismo metafísico: ontológico (se trata de encontrar lo realmente Real frente a lo aparente), gnoseológico (se trata de encontrar la Verdad frente a la opinión) y axiológico (se trata de encontrar lo Bueno frente a lo conveniente). Pues bien, si hay un empeño permanente en el pensamiento rortiano, ése reside en la lucha contra el dualismo metafísico ${ }^{5}$, y dado que es en este dualismo donde se funda el dualismo entre filosofía y retórica, esa lucha impliciter lo será también contra este último dualismo, y en la medida en que Rorty salga victorioso de su empeño también se verá derrotada la mutua separación de lo retórico y lo filosófico ${ }^{6}$. Con lo que resulta que la cuestión de la retórica es central, por poco que sea explícita, en el pensamiento rortiano. Así, su defensa del carácter discursivo y no absoluto del conocimiento, un conocimiento que es antes determinado por la propia comunidad que por cualquier correspondencia con la verdad, un conocimiento que es plural, esto es, que emerge bajo la forma de vocabularios que compiten por el reconocimiento, un conocimiento que busca antes la conversación que la objetividad, o sea, que trata de decir algo antes que de contribuir a la investigación, denota una preferencia por la comunicación «oral», comporta un inequívoco sesgo retórico. Y esto es lo que vamos a argumentar aquí: la centralidad retórica del pensamiento de Rorty ${ }^{7}$.

«Sin embargo, los que ya se han convertido al neopragmatismo no tomarán equivocadamente los enunciados de Rorty por vehículos portadores de la verdad ni por expresiones de creencias verídicas, sino que los reconocerán como recursos retóricos para influir en las creencias y las actitudes de la gente. Bajo una descripción que despoja de significado las cuestiones relativas a la verdad y la racionalidad, lo único que puede socializar a la gente en un nuevo lenguaje es la "persuasión"». Estas palabras, aunque dirigidas como un reproche a su destinatario, dan en el clavo de la posición retórica de Rorty. Su autor es J. Habermas ${ }^{8}$. Precisamente, en una entrevista concedida en Alemania, bajo el título de "Persuadir es bueno. Un diálogo con Richard Rorty», el americano responde a la cuestión "¿Entonces, en qué sentido los argumentos son "puramente retóricos"?» con su pronunciamiento posiblemente más explícito sobre el entreverado de la retórica en la filosofía: «Algunos filósofos ven una diferencia esencial entre lógica y retórica o entre "convencer" y "persuadir". Yo no la veo. Hay una diferencia entre argumentos buenos y malos, pero esta referencia se refiere al público o a los destinatarios. Un argumento es bueno para el público cuando a este le parecen plausibles las premisas del argumento. También existe una diferencia entre argumentos sinceros y no sinceros. Los primeros son de tal índole que aquellos que los proponen lo hacen porque ellos mismos están convencidos de ellos. Pero no creo que necesitemos diferenciar entre argumentos

\footnotetext{
5 «Si tuviéramos que buscar una manera rápida de describirnos tal vez lo mejor sería calificarnos de antidualistas», escribe Rorty en «El desafío del relativismo», en NIZNIK, J. - SANDERS, J. T., (2000), p. 53.

6 CAlder, G., (2003), p. 19: «La típica estrategia retórica rortiana es la de establecer una oposición entre los distintos lados de algún debate filosófico clave y demostrar entonces por qué el problema central que los divide no es en realidad un problema». En cierto modo, será esta estrategia la que haremos nuestra aquí respecto al debate entre filosofía y retórica.

Cf. Horne, J. S., (1989), pp. 247-248; Leff, M., (1978); Carter, K. - Presnell, M., (1994), p. 5; Horne, J. S., «Changing the subject: Rorty and contemporary rhetorical theory», y PRESNELL, M., «Icons, fragments, and ironists: Richard Rorty and contemporary rhetorical criticism», en LANGNSDORF, L. - SMITH, A. R., (1995), pp. 235-249 у 251-269.

8 Habermas, J., "El manejo de las contingencias y el retorno del historicismo», en NIzNIK, J. - SANDERS, J. T., (2000), p. 35 (traducción levemente modificada).
} 
lógicos y argumentos "puramente retóricos". Yo sustituiría la distinción que hace Habermas entre el uso estratégico y no estratégico del lenguaje por la distinción del common sense entre intentos sinceros y no sinceros de persuadir» ${ }^{9}$. Toda la filosofía rortiana viene a constituir un aval implícito de esta contundente respuesta. Veamos a partir de aquí, y teniendo en cuenta que tal vez la manera más común de definir la retórica sea considerarla como «arte de la persuasión», la conexión explícita.

Sólo desde fuera considerado, se puede afirmar que Rorty tenga un punto de vista ontológico. Desde el interior de su planteamiento la cuestión de un orden transcendental no se plantea, toda vez que, de entrada, rechaza la madre de toda metafísica, la dicotomía realidad/apariencia. Y no, desde luego, para hacer de la apariencia realidad, sino para salirse de cualquier jerarquía que divida lo que hay en un sector realmente real y otro aparentemente real. Él prefiere reemplazar esa dualidad para poner en su lugar otras como la contraposición entre pasado y futuro o entre lo útil y lo inútil ${ }^{10}$. De hecho, se vale de la distinción entre lo más y lo menos útil para esquivar la cuestión ontológica. El antifundacionalismo rortiano nunca afirma que no haya fundamento, simplemente no considera útil su cuestión. De modo que no se trata de que no exista aquello de lo que la tradición platónica se ha venido ocupando, mientras que sí existiría aquello de lo que se ocupa la tradición pragmatista en la que se autoinserta Rorty. El asunto no es el de la existencia del fundamento, sino el de su utilidad. Fundamento y utilidad están en planos distintos: no es que lo real sea lo útil y lo aparente lo inútil, sino que la bina fundamental entre lo real y lo aparente, que tan útil le fue a la tradición, simplemente ya no es útil. Esas piezas del vocabulario metafísico fueron útiles en su momento, pero ya no.

Así las cosas, sería inútil decir que la utilidad se convierte en Rorty en el nuevo fundamento o en el criterio fundamental. Si es criterio, la utilidad es un criterio retórico, no metafísico. Esto lo afirma expresamente en uno de sus no tan abundantes momentos de «autoconciencia retórica»: «La cuestión no reside en saber si nuestros criterios son utilitarios, sino en saber si podemos encontrar una fórmula menos vacua que la de "creencias más útiles" o "creencias de las que se piensa que producen mayor felicidad". Los pragmatistas piensan que, una vez abandonada la noción de correspondencia con la realidad, no podremos hacerlo. No es que sientan especial cariño por el término "útil". Lo usan solamente como recurso retórico cómodo para oponer su punto de vista a los puntos de vista de quienes piensan que "la persecución de la verdad" es una manera no vacua de describir el objetivo de esa deliberación y que contrasta con la persecución de la utilidad» ${ }^{11}$.

Aquí nuestro autor se cura en salud: se viene a «autoinculpar» como retórico. Reconoce abiertamente el carácter retórico de la utilidad: la utilidad es una vacuidad retóri-

9 RoRty, R., (2002), p. 162 (traducción levemente modificada).

10 Rorty, R., (1996a), p. 13: «He llegado al convencimiento de que la doctrina central del pragmatismo representa la propuesta de reemplazar la distinción entre apariencia y realidad - y entre la naturaleza intrínseca de algo y sus "características meramente relacionales"- por la distinción entre descripciones más útiles y descripciones menos útiles de las cosas».

11 Rorty, R., «Respuesta a Kolakowski», en NizniK, J. - SANDERS, J. T., (2000), p. 87. Ahí mismo vuelve a insistir, retorsión mediante, en que la noción de «utilidad» no tiene otra utilidad que la de servir de "contrapeso retórico» de otras vacuidades como la «verdad». Por eso afirmamos que no se puede confundir la utilidad con el fundamento: están a distinto nivel. 
ca. Pero ese vacío no se contrapone a un lleno de verdad. Perseguir la utilidad puede equiparase a perseguir la verdad siempre y cuando se acepte la recíproca vaciedad de la fórmula "perseguir la verdad». Si esto es lo propio de la filosofía, tampoco escapa ésta de la retórica. Así, procede Rorty implícitamente a la retorsión de la filosofía (fundacionalista). Desde ésta se le podrá «acusar» de retórico, pero él devolverá siempre la acusación ${ }^{12}$ : "Los pragmatistas piensan que la afirmación “ideseo la verdad!" no nos dice nada acerca del hablante, o al menos nada más que la afirmación "¡deseo la utilidad!". Todo el mundo desea la verdad y todo el mundo desea la utilidad. La cuestión es si, a los fines de formular una autodescripción en el nivel de la generalidad en que opera tradicionalmente la filosofía, una vacuidad presta mejor servicio que la otra. En ausencia de correspondencia con la realidad, las dos van unidas. Los pragmatistas piensan que una vacuidad es mejor que dos, puesto que evita los seudocontrastes» ${ }^{13}$.

Suena claro, entonces, que sustituir la oposición entre realidad y apariencias por la de utilidad e inutilidad no equivale a haber encontrado, por fin, el modo en que las cosas son como son, el orden natural del ser, la realidad. Este «logro» sólo sería posible en el interior de la oposición que el pragmatismo desplaza. Al contraponer lo más a lo menos útil Rorty se está moviendo en el exterior del círculo metafísico, le está trazando una tangente para salirse por ella ${ }^{14}$. Nótese que esa tangente es retórica. Rorty se mueve en el seno de la persuasión, está proponiendo un cambio de imagen, no está apelando a un fundamento real, sino a una imagen nueva. Por la tangente retórica se sale de la metafísica. En consecuencia, el reemplazo de una oposición por otra no obedece a un desacuerdo teórico, factible sólo dentro de la metafísica, sino a una circunvención de la propia teoría mediante la práctica. Se trata de un desacuerdo práctico en torno a qué estrategia filosófica pueda ser más provechosa. Él opta en su imagen por «renunciar a la idea de que hay algo que puede acercar a los seres humanos a lo correcto siempre que deambulan sin rumbo o eligen un camino incorrecto: algo como Dios, la realidad o la naturaleza humana» ${ }^{15}$. Optar por esta imagen de renuncia a las «altas instancias» no es negarlas en cuanto carentes de razón o falsas. Es prescindir de ellas (ponerlas pragmáticamente entre paréntesis) en aras de otras y mejores consecuencias generales.

Ahí anida la continua apelación rortiana al futuro. De hecho, «utilidad» se asocia indisolublemente en su perspectiva filosófica a «futuro mejor», pues si lo real era eterno, sólo al renunciar a lo intemporal se hace relevante el tiempo y la esperanza por otro mundo, el definitivamente real, se puede tornar en esperanza dirigida al futuro. Y esto es ir más allá de la metafísica, toda vez que «ir más allá de la metafísica sería dejar de hacer la pregunta acerca de qué es real y qué no lo es» ${ }^{16}$. Por eso la renuncia a la distinción entre apariencias y realidad, que posibilita las disputas metafísicas, además de reconvertirse en la distinción entre lo menos y lo más útil, la traduce oponiendo el pasado al futuro. Que en

12 En Rorty, R., (2000a), p. 87, se nos brinda el esquema de esa retorsión: "A quien dijese que eso, en vez de un "argumento" es mera "retórica" [...] le replicaría que no es ni más ni menos retórico o argumentativo que el intento de mis adversarios de describir [...]».

13 Rorty, R., «Respuesta a Kolakowski», en NizniK, J. - SANDERS, J. T., (2000), p. 87.

14 Su «apócrifo» Filosofía y futuro se dedica a ese trazado. Así, Rorty, R., (2002), pp. 9-10: «Cuando logramos una revolución socioeconómica exitosa o cuando adoptamos o perdemos cierta fe religiosa, no hay motivo para decir que esto nos ha acercado más a la manera en que las cosas son realmente. Podemos prescindir de la imagen de unos seres humanos apartando apariencias engañosas para obtener un vislumbre de la realidad y entrando de este modo en contacto con algo establecido y determinado que había estado ahí todo el tiempo. Nos irá mejor sin esa imagen».

15 RoRTy, R., (2002), pp. 11-12.

16 Rorty, R., (2002), p. 128. 
lugar de buscar la naturaleza intrínseca de lo real, Rorty prefiera forjar el futuro es lo que hace de él un postmoderno atípico. No obstante, recusa el adjetivo («equívoco e inútil») ${ }^{17}$, como todos los que se refieran a «movimientos» (los cuales "causan más problemas de los que solucionan»), en lugar de a "campañas» ${ }^{18}$. Y no puede ser menos, pues si su antifundacionalismo lo lleva a la anulación de todo deseo de realidad, el reemplazo de éste por el deseo de futuro lo ubica dentro de los más característicos ideales modernos, incluso o, por mejor decir, sobre todo, en lo que éstos tienen de prolongación de la escatología tradicional. Es este deseo lo que hace que «esperanza» sea término favorito de su retórica particular y que incluya en su léxico básico términos tan alejados de los planteamientos postmodernos como "progreso», «libertad», «utopía», «felicidad» o «esperanza». Es el presupuesto elpidológico la basa de la columna vertebral de toda su filosofía políticosocial, la «solidaridad», reactualización o continuación por otros medios de la caridad cristiana $^{19}$. Su ideología se inscribe, así pues, dentro del proceso secularizador de la modernidad $^{20}$, por mucho que repela toda macropalabra que pretenda englobar el «espíritu de la época» haciendo suyo como lema el título del libro de B. Latour, We have never been moderns ${ }^{21}$. Tan es así que lo que paradójicamente hace del suyo un planteamiento postmoderno es el llevar a ultranza la secularización moderna. Casi se podría aseverar que lo que hace Rorty es depurar los residuos premodernos de los grandes ideales de la modernidad, decantar sus posos metafísicos, para destilar su quintaesencia moderna. Es como si los modernos no hubieran sido suficientemente modernos por haber seguido venerando algo con tan poco futuro como el fundamento, como si queriendo mirar adelante aún mirasen arriba. De modo que el "postmoderno» Rorty suena a moderno sin fundamento.

Sólo desde fuera considerado, se puede afirmar que Rorty tenga un punto de vista gnoseológico. Desde el interior de su planteamiento la cuestión de un conocimiento transcendental no se plantea, toda vez que, de entrada, rechaza la madre de toda gnoseología, la dicotomía verdad/opinión. Y no, desde luego, para hacer de la opinión verdad, sino para salirse de cualquier jerarquía que divida lo que conocemos en un sector realmente verda-

17 RoRTy, R., (1999), p.13. Afín es el pronunciamiento en RoRTY, R., (2002), p. 102, y ya se decía en RoRTY, R., (2000b), p. 253: "No soy amigo del término "posmodernidad” (aquí se acusa a muchos postmodernos de «nadar y guardar la ropa»). No obstante, valga la precisión en RoRTY, R., (1993), p. 22: «Mis ensayos deben entenderse como muestras de lo que un grupo de filósofos italianos actuales han denominado "pensamiento débil” », y la simpatía declarada por «los pensadores antimetafísicos, "posmodernos” » en RoRTY, R., (2000a), p. 96. Y sobre ser "postmoderno" como reproche procedente de cierta izquierda intelectual, véase RoRTY, R., (1998), p. 28. A tenor de esto se impone la conclusión de que, aun cuando no se quiera ver contradicción fuerte en la actitud de Rorty respecto a su "condición postmoderna», incurre en todo caso en ambigüedades que revelan la manifiesta dificultad para ser (auto)considerado "postmoderno».

18 Cf. Rorty, R., (1998), pp. 67-79 («Movimientos y campañas»).

19 También esta confianza en el futuro es responsable, más allá de lo que dice, de lo que Rorty calla. Que nadie busque en este "postmoderno» el tratamiento de tópicos tan frecuentes en otros autores de la postmodernidad como el «nihilismo», el «fin de la historia», la "dramatización del fracaso de las metanarrativas» o del lugar común que identifica la racionalidad tecnológica con la racionalidad metafísica.

20 RoRTy, R., (2002), p. 14: «Me gusta pensar que la perspectiva filosófica que sugiero es una extensión natural del proceso de secularización que empezó en el Renacimiento y se aceleró en el siglo XVIII. La secularización ha incrementado la felicidad humana».

${ }^{21}$ Cf. Rorty, R., (1998), p. 75. 
dero y otro aparentemente verdadero. Este planteamiento no gnoseológico es coherente con el planteamiento no ontológico y arrastra consigo todo su ingrediente retórico. De hecho, lo refuerza. En efecto, al antifundacionalismo le corresponde un antirrepresentacionalismo en lo relativo al conocimiento, que fortalece la centralidad retórica de la filosofía rortiana ${ }^{22}$.

La posición propia de Rorty en el ámbito epistemológico parte precisamente del rechazo de un conocimiento reproductivo. Si pragmáticamente se prescinde de la idea de una realidad realmente real, no cabe entonces plantearse el saber como adecuación o correspondencia con lo real. Aquí es como si, aun cuando con un propósito inverso al de los griegos, recogiese la ambigüedad de ónta y mè onta que hacen referencia no sólo a lo que es y a lo que no es, sino también simultáneamente a lo que es verdad y a lo que no es verdad ${ }^{23}$. Perdida toda importancia de plantearse la cuestión del Ser, perdida toda importancia de plantarse la cuestión de la Verdad; al menos, de la verdad en mayúsculo singular. Rorty dice siempre no tener ninguna teoría de la verdad. La única acepción de «verdad» con que él trabaja es la de verdad como propiedad de los enunciados, una verdad adjetiva. En ningún caso, como propiedad o atributo del ser o de la realidad, una verdad substantiva ${ }^{24}$. Carece de sentido para nuestro autor lo que es presupuesto implícito de la acepción rechazada; a saber, que hay enunciados que no están en contacto con la realidad. Según Rorty, diríamos que a consecuencia de su apuesta por un conocimiento productivo en lugar de reproductivo, de su concepción instrumental del lenguaje, no hay manera de no estar en la realidad ${ }^{25}$.

Y es que plantearse la cuestión del «contacto» de la mente con la realidad presupone la posibilidad del no contacto, lo cual presupone, a su vez, la separación previa de la mente y la realidad, es decir, la disyunción polar entre la mente o espacio interior, lo espiritual, y lo otro de la mente o espacio exterior, lo corpóreo. O dicho en términos del propio autor: "La mera idea de "estar fuera de contacto con la realidad" presupone la imagen cartesiana, no darwiniana, de una mente que de alguna manera es ajena a las fuerzas causales que afectan al cuerpo. La mente humana es una entidad cuyas relaciones con el resto del universo son más bien representacionales que causales» ${ }^{26}$. En esto reside el propósito

22 Horne, J. S., (1989), pp. 256-257, partiendo de la declaración rortiana de que al carecer de epistemología, uno excluye también la relativista, afirma: «En tanto que Rorty no tiene una epistemología, tiene muy ciertamente una retórica. Lo seductor de Rorty consiste en el hecho de que su camino lleva directamente a la retórica».

${ }^{23}$ Cf. Lloyd, G. E. R., (1987), pp. 111 ss. Es como si Rorty reencarnase a Protágoras o a los hermanos también sofistas, esto es, «retóricos», Eutidemo y Dionisidoro arguyendo que es imposible desmentir o contradecir a alguien, o al cínico Antístenes sosteniendo la imposibilidad de la contradicción. Ya el propio Cratilo había equiparado el pseudé legein a mè ónta legein con lo que el enunciado falso es imposible.

${ }^{24}$ RoRTy, R., (2000b), p. 15: "Cuando hipostasiamos el adjetivo “verdadero" como "Verdad" y nos preguntamos por nuestra relación con ella, resulta que no tenemos absolutamente nada que decir», y p. 113: "Para los pragmatistas, el adjetivo "verdadero" es una herramienta perfectamente útil, pero el uso del substantivo "verdad" como nombre de un objeto de deseo es una reliquia de otra época: la época en la que creíamos que había un orden natural que entender».

${ }_{25}$ Rorty, R., «Relativismo: descubrir e inventar», en NIZnIK, J. - SANDERs, J. T., (2000), p. 57: «Ver el empleo de palabras como el uso de herramientas para manipular el medio y no como un intento de representar la naturaleza intrínseca de ese medio equivale a rechazar la pregunta sobre si la mente humana está en contacto con la realidad, pregunta que plantean los escépticos epistemológicos. Ningún organismo, ni humano ni no humano, está nunca en mayor o menor contacto con la realidad que ningún otro organismo». De alguna manera, y dicho sea de pasada, es como si Rorty viniese a hacerse eco del dilema antiguo del «enunciado falso», que tanto ocupó, entre otros, a Platón y Aristóteles, y que deriva de la ambigüedad anteriormente señalada de que ser y verdad significan lo mismo en el sentido de que un mismo término refiere ambas cosas. Dejando a un lado el planteamiento clásico del dilema y las soluciones ofrecidas, en el caso rortiano el enunciado falso es imposible si se lo considera exento, fuera del contexto de un determinado «léxico último».

${ }^{26}$ Rorty, R., «Relativismo: descubrir e inventar», en NiznIK, J. - SANDERS, J. T., (2000), pp. 57-58. 
del antirrepresentacionalismo rortiano, en que «para convertir por completo nuestro pensamiento al darwinismo, tenemos necesidad de dejar de concebir las palabras como representaciones y comenzar a pensar en ellas como nudos en la red causal que liga el organismo a su medio ${ }^{27}$. Rorty pone en cuestión la jerarquía sensual oculocéntrica en su crítica a la imagen de la mente como espejo, que, aun cuando fuese Descartes quien puliese nuestra "esencia de vidrio», ya había estado dominando la tradición desde que la filosofía debelase a la retórica (sofista) que se centraba en el oído, el más temporal de los sentidos. La mirada hacia arriba, la «mirada sostenida de la mente», en términos de M. Jay ${ }^{28}$, es la mirada de la representación, que observa sin implicarse con el objeto de su mirada, objetivamente, mente objetiva. Es en este privilegio de la mirada, que otorga todas las prerrogativas cognoscitivas al «estasis sincrónico», por decirlo con H. Jonas ${ }^{29}$, elevando al Ser estático por encima del devenir de los seres, a las esencias fijas sobre las dinámicas apariencias, en el que se basa el dualismo realidad-verdad/apariencias-opiniones, donde anida consecuentemente la dicotomía entre filosofía y retórica. Y es que, como sostiene Holmberg al analizar la claridad como metáfora visual, «la entera concepción del logos como teniendo que ver con el Ser como verdad llegó a implicar la experiencia del ser en términos de corrección ${ }^{30}$. Cuando, por el contrario, Rorty lleva a ultranza la crítica de Dewey a la spectator theory of knowledge, está abogando implícitamente por la supresión de esa dicotomía, a favor del inevitable intercalado de lo retórico en el pensamiento.

\section{IV}

En efecto, la polaridad entre filosofía y retórica es, como viene a enseñar el padre de la nouvelle rhétorique, Perelman ${ }^{31}$, paralela a la que se establece entre realidad y apariencias y entre verdad y opinión, y, tal y como lo muestra Rorty, estas últimas polaridades arrancan de la metáfora ocular. La distinción entre el ojo divino, la visión intelectual en la que se basa la episteme, y el órgano de la vista, la visión sensorial, en la que se basa la doxa, permite distinguir dos planos en la realidad, el inferior de la apariencia y el superior de la verdadera realidad. Esta imagen se apoderó de la imaginación de los fundadores del pensamiento occidental, con la consecuencia de que el conocer se identificó con ver, con un proceso igual al de mirar algo. Y permitió, por añadidura, el establecimiento de una relación metafísica privilegiada entre el intelecto y la realidad-verdad última. La posibilidad de este privilegio vendría dada por la naturaleza común: así como el ojo corporal puede ver por participar de la naturaleza del sol, la fuente de la luz, el ojo mental puede ver las ideas por participar de su naturaleza, el intelecto es connatural a las ideas. Este privilegio sería exclusivo de la naturaleza humana: el hombre es singular por tener un alma inmaterial capaz de contemplar los universales. Esta tensión entre lo material e inmaterial de la naturaleza humana cristalizó, y nunca mejor dicho, en la visión de la mente como «espejo de la naturaleza». La mente sería un espejo porque como tal reflejaría sin verse afectada o alterada por la imagen reflejada: reflejaría formas sin cam-

\footnotetext{
27 Rorty, R., «Relativismo: descubrir e inventar», en NIZnIK, J. - SANDERS, J. T., (2000), p. 58.

28 Cf. JAY, M., (1994).

29 Cf. Honas, H., (1997) y JaY, M., (1994), p. 55 y p. 24.

30 Holmberg, C., (1977), pp. 232-233.

31 Cf. Perelman, CH. (1989), p. 464. Debemos a Perelman la inspiración a la hora de destacar la centralidad retórica de la filosofía - cf. Marín-CASANOva, J. A., (1999).
} 
biar ella de forma; y porque como los espejos estaría hecha de algo más sutil que los órganos físicos. Rorty insiste en que esta imagen ha resistido hasta hoy, más allá del hecho de que las ideas platónicas ya no sean creídas, persistiendo siempre que se señala una discontinuidad entre la naturaleza humana y la no humana ${ }^{32}$ y se pretende hacer patente esa discontinuidad en las formas de conocimiento que supuestamente tratan con los universales ${ }^{33}$ como es el caso de la filosofía. De la filosofía sin retórica, añadiríamos.

Rorty recurre, así pues, a «la Biología como antidualismo» ${ }^{34}$, a la Biología darwinista, que destrona a la especie humana para ponerla en continuidad con el resto de las especies sin que, en consecuencia, se le pueda atribuir alguna misión teleológica particular: no somos la especie elegida ${ }^{35}$. Ahora bien, señalada la continuidad animal-humano, lo que aquí centra nuestra atención no es el planteamiento biológico explícito, sino el retórico implícito. Al respecto, es menester subrayar dentro de la redescripción de Darwin el valor que le atribuye Rorty de poner en duda «la esperanza de escapar a la temporalidad» ${ }^{36}$, la esperanza aniquiladora del, como arriba lo hemos denominado, "deseo de futuro», pues el planteamiento biológico catapulta el retórico. En efecto, es la temporalidad, como señaló Perelman ${ }^{37}$, carácter de la argumentación retórica que la distingue diametralmente de la argumentación lógica o demostración, la propia de la filosofía oculocéntrica. La diferencia es "esencial», toda vez que el tiempo no desempeña rol alguno cuando la filosofía es espejo de la naturaleza, una naturaleza siempre intemporal. Pero lo desempeña de forma capital cuando se refleja en el «caleidófono» de la retórica. Tan primordial es su papel que cabe preguntarse si no es la intervención del tiempo lo que mejor permite distinguir el razonamiento retórico del filosófico (tradicional). Y si, a su vez, cabe preguntarse si la «temporalización de todo» no será lo más definitorio del proyecto antidualista rortiano, entonces, más allá de que sus pronunciamientos sobre la retórica sólo sean ocasionales, se podría concluir afirmando la centralidad retórica de la filosofía de Rorty ${ }^{38}$.

32 RoRTy, R., (2000b), p. 59: «Si, como buenos darwinistas, deseamos introducir el menor número posible de discontinuidades en la narración de nuestro camino desde el simio a la Ilustración, rechazaremos la idea de que la naturaleza haya establecido una única función input-output que, encarnada en cada miembro de nuestra especie, nos capacite para representar el entorno con exactitud».

${ }_{33}$ RoRty, R., (1989), p. 49: «Sugerir que no existen los universales — que son flatus vocis- es poner en peligro nuestro carácter único. Decir que la mente es el cerebro es dar a entender que segregamos teoremas y sinfonías de la misma manera que nuestro bazo segrega malos humores».

34 Cf. Álvarez, A., (2000).

35 Que nuestra «especie biológica lleva consigo determinados "derechos" » es un «consuelo metafísico» que se denuncia en RoRTY, R., (1996b), p. 52.

36 RorTy, R., (2002), p. 18, redescribe la tesis evolucionista «según la cual deberíamos entender a los seres humanos como animales más complejos y no como animales dotados de un rasgo característico adicional, llamado "entendimiento" o "alma racional". Esta tesis no sólo pone en duda la esperanza a escapar de la temporalidad, sino también la distinción entre la adaptación a la realidad y el conocimiento de la realidad [...]. Ahora bien, esto significaba aportar nuevas descripciones de la relación entre la evolución biológica y la cultura que permitieran borrar la distinción entre naturaleza y espíritu [...]».

37 Cf. Perelman, CH., (1989), pp. 437 ss.

38 No puede ser mera coincidencia que Rorty, desechada la verdad substantiva, recurra a la "veracidad», algo de raigambre retórica, y que la ligue a la temporalidad. Así, en RoRTy, R., (2002), pp. 25-26, leemos: «En los tiempos recientes hemos estado hablando menos de la verdad y más de la veracidad, menos de llevar la verdad al poder que de la posibilidad de cuidar de que el poder se ejerza de manera honesta. Este cambio me parece saludable. La verdad es atemporal y eterna, sólo que no se sabe bien cuándo se está en posesión de ella. La veracidad, en cambio, es temporal, contingente y frágil, como también la libertad. Sin embargo, podemos reconocer a ambas cuando las poseemos». Esta estrategia antiesencialista respecto de la verdad tiene su eco en la opción coherentista, en la investigación como «recontextualización», en la verdad como coherencia — cf. RoRTY, R., (1996b), p. 141. 
Y es que la filosofía tradicional, «theórica», ésa contra la que nuestro autor carga sus acentos más críticos, se presenta desde los tiempos griegos y más aún en los modernos, en su hipóstasis racionalista, y todavía en los actuales, al menos, en su faceta analítica, como una enfilada de estructuras y formas que podría ser dada de golpe, en una sola tacada, instantáneamente, pues nada nuevo se inserta en curso de ruta, nada de lo que está dado se modifica. Por eso —aplicando las palabras de Perelman a lo que el neopragmatista plantea- «la demostración no se dirigirá a todo el hombre sino a ciertas facultades intemporales, así el entendimiento, la razón » ${ }^{39}$, es decir, a facultades que sólo podemos admitir si admitimos la discontinuidad absoluta del hombre respecto de los demás vivientes. Por el contrario, la argumentación (retórica) es una acción que como tal comprometiendo a agentes personales no puede sustraerse al tiempo: «Es preciso necesariamente argumentar en el tiempo y bajo su imperio ${ }^{40}$. Ciertamente, a diferencia de la demostración (filosófica), la argumentación busca promover la adhesión de un auditorio, siempre circunstancial, nunca universal. El auditorio se encuentra en un contexto que no puede librarse de la temporalidad. No sólo el auditorio está en el tiempo, sino que la acción que se quiere provocar en él está condicionada por el tiempo. La acción pretendida requiere tiempo para realizarse, por un lado; por otro, el efecto de la argumentación retórica no es definitivo, pues la adhesión, que también exige tiempo para producir su efecto, es susceptible de modificación en el tiempo, es decir, siempre resulta provisional, la argumentación nunca está cerrada: «Y es que toda toma de posición es precaria, que toda argumentación se inserta en un contexto perpetuamente modificable. Y es que también los argumentos que han parecido suficientes para arrastrar a una decisión podrían no ser quizá válidos para un auditorio diferente» ${ }^{41}$. Todo esto que liga la retórica a los cambios comportados por el tiempo, que transforma las condiciones mismas del razonamiento, cambio de la persona, cambio del contexto argumentativo, podría inscribirse sin reparo en la partitura rortiana. De hecho, Perelman, quien quizá nunca supiera nada del americano (murió en 1984), observa que la argumentación de los antiguos griegos se volcaba antes sobre el pasado que sobre el futuro, debido a que conducía sobre todo a una visión y ello porque su tendencia filosófica general era la contemplación, de donde su esfuerzo hacia la intemporalidad, mientras que hoy la propensión del tiempo, con el pensamiento histórico, con el evolucionismo, con las filosofías de la acción, se ha hecho eminente, de modo que, en contraste con la griega, «una mirada más rica que aquellas, y también las concepciones con las que nos han familiarizado filosofías más recientes, notablemente el pragmatismo, ayuda hoy a discernir el aspecto activo de la argumentación» ${ }^{42}$.

A mayor abundancia del ingrediente temporal propio de lo retórico, Perelman señala otro elemento característico de la argumentación frente a la demostración que justamente es Leitmotiv recurrente en Rorty y que, en consecuencia, permite de nuevo calificar su pensamiento como retórico. Nos referimos a la ciceroniana indistinción entre lenguaje y objetos de lenguaje ${ }^{43}$. Lo habitual de las filosofías basadas en la demostración, las que Perelman llamaba «absolutas» y que vienen a coincidir con las que rortianamente se miran en el espejo de la naturaleza, en contraste con los incesantes cambios retóricos

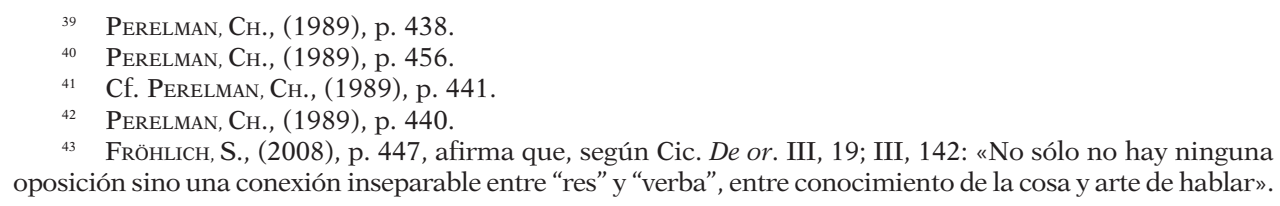

43 Fröhlich, S., (2008), p. 447, afirma que, según Cic. De or. III, 19; III, 142: «No sólo no hay ninguna oposición sino una conexión inseparable entre "res" y "verba", entre conocimiento de la cosa y arte de hablar». 
de niveles o mezcla de la reflexión sobre el discurso con el objeto del discurso, es la tajante distinción de niveles, la separación del metalenguaje respecto del lenguaje, que se remonta al luminoso y radical divorcio entre las palabras y las cosas ${ }^{44}$.

Pues bien, la obra rortiana está plagada, en general, de esta retórica indistinción de niveles «argumentativa»: «La distinción entre uso y mención es sólo una distracción» ${ }^{45}$. Todo el brío compositivo de Rorty en aras de la superación de los dualismos proyectados por la imagen vítrea puede ser entendido como un ejemplo de ejercicio permanente de semejante indistinción, de cancelación de la bina fundamental, que distingue al pensamiento de su expresión, que disyunta el contenido de la forma, la «realidad» del lenguaje que la expresa ${ }^{46}$. Y es que es tras la escisión abisal entre las palabras y las $\operatorname{cosas}^{47}$ que se esconde el punto ciego de la metáfora de la luz, merced a la cual resplandece la realidad-verdad sobre el trasfondo oscuro de la apariencia-falsedad.

Y por su explicitud, como plasmación de la inconveniencia de tomar por real la disyunción de las palabras y las cosas, se hace aconsejable recordar el sedicente panrelacionismo rortiano, el cual parte de la idea de que podemos fundir los ordines cognoscendi et essendi en uno solo, rechazando, por tanto, la distinción entre sujeto y objeto, entre aquellos elementos cognoscitivos resultantes de la mente y aquellos resultantes del mundo. "Cosa que se consigue afirmando que nada es lo que es bajo todas y cada una de sus descripciones; que la noción de lo que una cosa es en tanto que no descrita, con independencia de las relaciones que mantiene con las necesidades humanas y los intereses que han generado una u otra descripción, carece de sentido» ${ }^{48}$. Esto no significa que el lenguaje ocupe ahora el lugar de la realidad, una suerte de «idealismo lingüístico». Frente a la acusación de «lingüisticismo» o de "perder el contacto con el mundo», Rorty contesta que «aunque dejemos de describir el conocimiento sobre una cosa como una representación precisa de su naturaleza intrínseca y, de este modo, rompamos los vínculos representacionales con el mundo, no obstante mantenemos vínculos causales» ${ }^{49}$. Él lo que hace es aplicar el principio de parsimonia, la navaja de Ockham, y partiendo de que una propiedad es simplemente un predicado hipostasiado, funcionar intelectualmente no admitiendo propiedades que no puedan ser capturadas por el lenguaje. Es decir, aun-

${ }_{44}$ Perelman, $\mathrm{CH}_{\text {., }}$ (1989), p. 448: «Sucede incluso que distinciones entre lenguaje y objetos, entre lenguajes de diferentes niveles sean introducidas con el solo fin de jugar enseguida como factores de valorización o de desvalorización. Conocemos la depreciación que se les hace sufrir a determinados enunciados calificándolos como "palabras", por oposición a las "cosas". La disociación entre lo que es "verbal" y lo que es "real" no es sino, en cualquier caso, uno de los modos de depreciación vinculados a las diferenciaciones de niveles: semejante depreciación puede asimismo efectuarse disociando lo que es concepto válido de lo que no es sino ilusión de concepto, entendiendo por ahí lo que no debería figurar entre nuestros instrumentos de pensamiento».

45 RoRTY, R., (1991), p. 154

46 Contra un contenido verdadero presuntamente independiente de la forma afirma RoRTY, R., (1989), p. 325 , algo tan retórico como que «la forma en que se dicen las cosas es más importante que la posesión de verdades".

${ }_{47}$ RoRTY, R., (1993), p. 58: «En particular, la tradición ha sugerido que las palabras no son importantes. Desde que la filosofía ganó su disputa con la poesía, ha sido el pensamiento lo que cuenta - la proposición, algo que muchas oraciones expresan igualmente bien en muchos lenguajes-. De acuerdo con la concepción filosófica tradicional no es muy importante el que una oración sea hablada o escrita [...]. Pues las palabras son meros vehículos de algo menos frágil y transitorio que las marcas y ruidos. Los filósofos saben que lo que importa es la verdad literal, no una elección de fonemas, y con seg uridad no de metáforas. Lo literal dura y da poder. Lo metafórico — aquello que no puedes ni argüir ni justificar, aquello para lo que no puedes encontrar una paráfrasis no controvertida- es impotente. Pasa y no deja huella».

48 RoRty, R., (2000a), p. 141.

49 Rorty, R., (2000a), p. 141. 
que algunos puedan entender que Rorty está afirmando la inexistencia o irrealidad de propiedades extralingüísticas, lo que está queriendo decir es que la cuestión es la de dejar fuera la cuestión de la realidad. Ya lo vimos, la cuestión de la realidad (frente a las apariencias) no es que sea irreal, es inútil.

El procedimiento retórico que emplea él es justo el «argumento pragmático», descrito precisamente por Perelman como «un argumento de consecuencias que aprecia un acto, un evento, una regla o toda otra cosa, en función de sus consecuencias favorables o desfavorables; se transfiere así todo o parte del valor de éstas sobre lo que es considerado como causa u obstáculo» ${ }^{50}$. Igual se pronuncia Rorty: "Cuando se presenta una de estas alternativas, la debatimos, y no sobre la base de categorías o principios, sino de las respectivas ventajas y desventajas concretas que su aceptación reporta» ${ }^{51}$. Es esta estrategia retórica de caja negra (de puesta entre paréntesis de la naturaleza intrínseca de la cosa para atenerse al efecto de la cosa) la que sonoramente utiliza: «La predicación es una forma de relacionar unas cosas con otras, una forma de centrar la atención pública sobre unas determinadas redes de relaciones por encima de otras. Por consiguiente, todas las propiedades son hipóstasis de redes de relaciones. Es completamente indiferente que interpretemos esas relaciones en clave realista, como si ya estuvieran ahí antes de la invención de los predicados, o en clave antirrealista, como si empezaran a existir al tiempo que esas invenciones. Tal es el paradigma del tipo de cuestiones que los pragmatistas rechazan como irrelevante para la práctica y, por tanto, irrelevante tout court» ${ }^{52}$. Y esta irrelevancia viene dada porque lo importante pragmáticamente es mirar adelante y no mirar arriba. Un panrelacionista es automáticamente un pragmatista, no se plantea «representar las cosas con precisión», pues eso es recaer en el dualismo realidad/apariencia, privilegiar una descripción, considerar unas propiedades como esenciales y otras como accidentales. El razonamiento rortiano es — podría acusar no sin pruebas alguienciertamente circular, presupone lo que quiere concluir, lo que ocurre es - podría reargüir sin empacho el acusado- que (aparte de que la circularidad pragmáticamente es, antes que viciosa, virtuosa) el razonamiento de la tradición también adolece de circula$\operatorname{ridad}^{53}$. Por eso Rorty no va a argumentar en sentido fuerte contra la tradición, sino que la va a rodear llevando a cabo lo que podemos considerar una retorsión retórica de la misma: lejos de presentar una argumentación (fuerte) alternativa, se trata más bien de presentar una alternativa a la argumentación (fuerte) ${ }^{54}$.

50 Perelman, Ch., (1989), p. 19.

Rorty, R., (1996a), p. 250. Cf. Horne, J. S., (2001), pp. 152 ss.

RoRTy, R., (2000a), p. 142.

53 Cf. RoRTy, R., (1996b), p. 49.

54 Una alternativa netamente retórica o persuasiva — cf. Marín-CaSANova, J. A., (2011)—. Así, leemos en RoRTy, R., (1991), pp. 28-29: «De acuerdo con la concepción de esos temas que estoy presentando, no se les debiera solicitar a los filósofos argumentos contra [...]. Todo argumento según el cual el uso que corrientemente hacemos de un término corriente es vacío, o incoherente, o confuso, o vago, o "meramente metafórico", es forzosamente estéril e involucra una petición de principio. Porque un uso así es, después de todo, el paradigma de un habla corriente, significativa, literal [...] Raramente una filosofía interesante consiste en el examen de los pro y los contra de una tesis [...]. De acuerdo con mis propios preceptos, no he de ofrecer argumentos en contra del léxico que me propongo sustituir. En lugar de ello intentaré hacer que el léxico que prefiero se presente atractivo". Esto supone un avance respecto de La filosofía y el espejo de la naturaleza, del que es consciente el autor, como muestra la palinodia entonada en RORTY, R., (2000b), p. 125, n. 16: "Aún hacía yo por entonces la desafortunada distinción entre "demostrar que los filósofos anteriores estaban equivocados" y "ofrecer redescripciones en un lenguaje alternativo", en lugar de decir de un solo golpe que afirmar que los antepasados de uno usaban un mal lenguaje es lo mismo que afirmar que estaban cometiendo un cierto tipo de error». 
Respecto del lenguaje, el pensamiento rortiano empieza por negar la mayor: la suposición de que haya un Lenguaje. Al menos así, en mayúsculo singular. Esto es, un lenguaje primero, dado de una vez por todas y para siempre, a priori. Rorty desecha la imagen del lenguaje como medio transparente para representar la Realidad, puesto que no hay ninguna Realidad que representar: si no existe un Mundo Real significativo aparte de los significados con que los humanos lo constituyen, se vuelve redundante concebir el lenguaje como facultad innata de representación de lo Real. Justo por la índole lingüística de los significados que adscribimos o conferimos al mundo, en oposición a la visión del mundo como teniendo significados propios con los cuales corresponde el lenguaje, el lenguaje no puede ser el Lenguaje, sino, antes al contrario, un polifónico «instrumento conveniente».

Junto al rechazo de la visión de que haya alguna naturaleza intrínseca que haya de ser representada o expresada, en el repudio de la teoría correspondencialista de la verdad hay que añadir la radical distinción entre la afirmación de que el mundo esté ahí afuera (no la Realidad, pero sí el mundo en cuanto no es nuestra creación, pues la mayor parte de las cosas en el espacio y el tiempo son efectos de causas ajenas a los estados mentales humanos) y la afirmación de que la verdad esté ahí afuera. Rorty no admite esta última afirmación, toda vez que, para él, sin enunciados no hay verdad. Y como los enunciados no están ahí afuera, o sea, no existen por separado o independientemente de la mente humana, la verdad no puede estarlo tampoco. O dicho con toda sonoridad: el mundo está ahí afuera, pero las descripciones del mundo no. Sólo las descripciones del mundo pueden ser verdaderas o falsas, pero el mundo no puede ser verdadero o falso. Sin la «ayuda» de las actividades descriptoras de los humanos carece de sentido atribuir verdad (o falsedad) al mundo. Se constata así que las dos cosas van ligadas, la (no) postura ontológica y la (no) postura gnoseológica: desechada la utilidad de la Realidad, desechada la utilidad de la Verdad. Para él la Verdad mayúscula, la Verdad del Ser, la Verdad Real, parece algo absurdo. Lejos de ser un transcendental, en la tesitura rortiana, la verdad no se descubre, no se encuentra, la verdad se hace (lo que no significa que se haya descubierto que no hay verdad ahí afuera).

En consecuencia, según Rorty, la consideración de que a la vez verdad y mundo están ahí afuera no obedece sino a la «herencia mitológica» de cuando el mundo era concebido como la creación de un Creador, de un Ser que tenía un Lenguaje propio, una Palabra, pero esa época es del pesado pasado, ha pasado cuando se trata de soltar lastres y abandonando el espíritu de la pesantez mirar al futuro: "Si desistimos del intento de dar sentido a la idea de tal lenguaje no humano, no incurriremos en la tentación de confundir la trivialidad de que el mundo puede hacer que tengamos razón al creer que una proposición es verdadera, con la afirmación de que el mundo, por su propia iniciativa, se descompone en trozos, con la forma de proposiciones, llamados "hechos" ${ }^{55}$. Por tanto, no es que no haya un mundo extralingüístico, sino que la verdad no es de este mundo: la verdad no es un hecho "natural», sino artificial, vinculado al lenguaje, un hecho lingüístico y consiguientemente humano. Sólo dentro del lenguaje hay hechos y sólo los hechos recortados previamente por el lenguaje determinan la verdad o falsedad de una proposición.

Ahora bien, así como, entre sentencias que compiten por la validez, el mundo «decide» efectivamente cuál es la verdadera, no hay manera de decidir la verdad del lenguaje en su

55 RoRTY, R., (1991), p. 25. 
conjunto: «Ningún lenguaje se ajusta más a la realidad que otro ${ }^{56}$. Cuando transitamos de enunciados singulares a vocabularios totales el mundo se queda mudo, toda vez que el mundo sólo «habla» a partir precisamente de vocabularios últimos: «Cuando la noción de "descripción del mundo" se traslada desde el nivel de las proposiciones reguladas por un criterio en el seno de un juego del lenguaje, a los juegos del lenguaje como conjuntos, juegos entre los que no elegimos por referencia a criterios, no puede darse ya un sentido claro a la idea de que el mundo decide qué descripciones son verdaderas y cuáles son falsas. Resulta difícil pensar que el léxico sea algo que ya está ahí afuera, en el mundo a la espera de que lo descubramos» ${ }^{57}$. Este punto es de vital importancia porque aquí enmudece la lógica y resuena la retórica con todo su rebato. En efecto, como no hay un Lenguaje Necesario, sino múltiples lenguajes contingentes, y no hay experiencia del mundo sans phrase, no hay modo de apelar al mundo para que valide un lenguaje particular. La lógica calla entonces y lo que habla es la persuasión. Al silencio de la lógica responde la voz de la retórica.

VI

Rorty no es tan explícito, pero algunos pronunciamientos expresos y las premisas de las que parte autorizan semejante conclusión. De entrada, el primer elemento retórico que hay que considerar viene dado por el hecho de que el mundo no propone un lenguaje para ser hablado (el lenguaje «natural» correspondiente a la naturaleza intrínseca del mundo) y por la consiguiente pluralidad de lenguajes (lenguajes artificiales, creaciones humanas): sólo los humanos pueden proponer lenguajes para hablar sobre el mundo. El problema de qué lenguaje elegir no lo puede resolver ningún algoritmo, el problema no es lógico, es retórico. Así, «el hecho de advertir que el mundo no nos dice cuáles son los juegos del lenguaje que debemos jugar no debe llevarnos a afirmar que es arbitraria la decisión acerca de cuál jugar» ${ }^{58}$. Por tanto, estamos ante la cuestión de la decisión, cuyo «rol ha sido demasiado negligentemente descuidado dentro de la teoría del conocimiento ${ }^{59}$, en opinión de Perelman, quien pretende reintegrarla dentro de su teoría de la argumentación contra la tradición racionalista y empirista de considerarla, cuando no hay evidencia, sans cause, arbitraria. Rorty, sin embargo, no pretende regular la decisión, sino mostrar que la decisión (incluida la "arbitraria») no obedece a criterios, no es ninguna decisión lógica, pues es la propia noción de criterio la que carece de sentido cuando se trata de cambio de juego del lenguaje: «La tentación de buscar criterios es una especie de la tentación, más general, de pensar que el mundo, o el ser humano, poseen una naturaleza intrínseca, una esencia. Es decir, es el resultado de la tentación de privilegiar a uno de los muchos lenguajes en los que habitualmente describimos el mundo o nos describimos a nosotros mismos ${ }^{60}$.

56 Rorty, R., (2002), p. 112. Esta tesis va asociada ahí a la de que la búsqueda de la objetividad lo es de un acuerdo entre sujetos, algo que requiere, añadamos nosotros, de mucha retórica. Y esto nos permite interpretar el «amor a la verdad» antes como «amor» a los otros que a lo otro (véase la p. 115). Lo que nos consiente entender, a su vez, otros lugares comunes rortianos, aquí no desarrollados, como el falibilismo y la sustitución de la autoridad por la fraternidad —cf. RoRTY, R., (2000a) — o el conocimiento por la esperanza —cf. RoRTY, R., (1997).

${ }_{57}$ RoRTY, R., (1991), p. 26.

58 Rorty, R., (1991), p. 26 (traducción levemente modificada).

59 Perelman, Ch., (1989), p. 423.

${ }^{60}$ RoRTY, R., (1991), p. 27. En R. RoRTy (2002), p. 130, se muestra cómo preguntar por el criterio de utilidad es algo anejo al esencialismo correspondencialista, no exento de consecuencias prácticas: «Opi- 
Es la tentación fundacionalista y representacionalista, en la que ha caído tradicionalmente el hombre serio de Occidente, del lenguaje perfecto, del grado cero de retórica, de la lógica pura, de lo que es la mente cuando no posee contaminación empírica alguna, esto es, una retícula de relaciones «mathemáticas», una mathesis universalis. Esa lógica es en todo forma, una forma independiente de todo ese contenido que gracias a ella es conocido en su verdad. Esta red lógica es un lenguaje perfecto, un lenguaje que se supone uno (universal) y terminado desde un principio (la lógica carece de historia), pues representa todo el espacio lógico posible, el universo de todo lo decible. La mathesis es una red que de antemano posee la forma o fórmula de todos sus contenidos posibles, los cuales, por eso mismo, no la modifican en nada, se limitan a ir rellenando sus celdas preexistentes, existentes a priori. Cambian los contenidos del lenguaje, pero éste mantiene inalterada su pureza: jamás, como el hamletiano Horacio, ve alterada su pureza. Lo que se contempla es entonces la verdad absoluta, una verdad universal y necesaria, la verdad eterna. Y una verdad sólo puede ser eterna, si es una verdad preexistente y resistente a los que la conocen. Así es la verdad que se concibe como algo que se descubre o encuentra, la verdad a la que se accede viéndola, contemplándola, o sea, «theóricamente», pues es una verdad que está ahí, cuya contemplación depende exclusivamente de la capacidad del que esté dispuesto a verla, pues ella permanece objetivamente idéntica para todo el mundo. Pero la verdad exenta de retórica sólo puede ser así para un mundo ya hecho, es decir, si presuponemos un mundo creado por un ser — dios o demiurgo- personal, dotado de un lenguaje propio cuya expresión literal es precisamente el mismo mundo, el cual se recorta en hechos autosubsistentes que son expresados por la verdad que los representa en su adecuación a ellos. He aquí la no justificada presuposición del isomorfismo entre mente y mundo, eso sí, mundo auténtico o «natural» en función del cual hay que depurar al meramente fáctico. Así las cosas, tenemos hechos extralingüísticos, y una conciencia extralingüística. Y esto es creer en el «dogma de la inmaculada percepción ${ }^{61}$, ya que sin este dogma es imposible la theoría, la mirada no interpretativa del referente.

Frente a ese ideal serio de pureza y perfección ${ }^{62}$, Rorty es "hombre retórico» cuando rechaza el dualismo contenido/forma o, como él dice siguiendo a Davidson, «esquema/ contenido", que subtiende a la tentación de privilegiar una sola descripción. Una implicación de ese rechazo es el desplazamiento de la cuestión del criterio (lógico). La cuestión no es si algo es arbitrario o está regido por criterios objetivos ni mucho menos invertir el canon criteriológico para reemplazar los criterios objetivos por criterios subjetivos. La cuestión es que los criterios no son cuestión, no lo son a la hora de cambiar de vocabulario, no son herramientas útiles para eso. Los criterios valen, podría decirse, ad intra, en el seno de un juego de lenguaje, pero no ad extra, cuando se trata de cambiar el juego, inter léxicos. Y es que cada juego define sus criterios, tiene su lógica, es decir, sus reglas, pero no se dispone de reglas cuando la jugada consiste en pasar de un juego a otro. No hay criterio general o universal ${ }^{63}$. Y es que, como ya hemos notado, los mismos criterios

nar que esta demanda de criterio siempre es pertinente es imaginar que el lenguaje del futuro deberá ser una herramienta en manos del lenguaje del presente. Es convertirse en un maniático del control, en alguien que cree que puede cortocircuitar la historia encontrando algo que yace más allá de la misma». Se comprueba así una vez más la ligazón rortiana entre utilidad y futuro (y libertad).

${ }^{61}$ Parry, D. M., (1991), p. 33.

${ }^{62}$ Cf. Rorty, R., (1996a), pp. 79-98 («Conservando la pureza de la filosofía»).

${ }_{63}$ Rorty, R., «Respuesta a Kolakowski», en NizniK, J. - SANDERS, J. T., (2000), p. 84: «Para los pragmatistas como Dewey las preguntas criteriológicas filosóficas generales no tienen respuestas, ni hacen falta. Las únicas preguntas criteriológicas que requieren respuesta son las de índole particular, regional. 
de utilidad apenas son útiles, concedido que «sean» ${ }^{64}$. Su estatuto no es «lógico», si acaso «retórico» ${ }^{65}$.

Estamos, así pues, ante una concepción no criterial de la racionalidad, reconocidamente persuasiva: "Como para nosotros "racional” significa meramente "persuasivo", "irracional" sólo puede significar "invocador de fuerza" ${ }^{66}$. En efecto, lo que aquí se está poniendo en tela de juicio implícitamente es la clásica distinción entre persuadir y convencer, una disyunción polar propia del «hombre serio» para desmarcarse del "retórico», que desdeña la adhesión del destinatario por irracional, por estar afecta de subjetividad, es decir, de pasión o emotividad. Desde Platón, por lo menos, el filósofo en tanto que antirretórico lo que quiere es convencer con la fuerza de la razón, hacer callar con sus demostraciones concluyentes, dejar que la objetividad se imponga impersonalmente por su propio peso. Rorty no cree que esa distinción sea fuerte ${ }^{67}$. Podría valer, en todo caso, intralingüística pero no interlingüísticamente: «Más bien, la importancia de la filosofía narrativa es que la persuasión es tan frecuentemente una cuestión de hacer que la gente deseche un vocabulario (y las cuestiones que ella enuncia en su seno) como de argumentación deductiva» ${ }^{68}$. Puestos a escorarse, lo hace a favor de la persuasión, pero no para sustituir la convicción por la persuasión, sino para destacar la inutilidad de la convicción a partir de demostraciones lógicas a la hora de abordar los cambios de lenguaje. No se puede prescindir del elemento suasivo cuando se pasa de un juego a otro juego de lenguaje ${ }^{69}$. A saber: las demostraciones constringentes, basadas en la convincente fuerza de la lógica, sólo son operativas contra proposiciones, pero no contra el conjunto de posibilidades proposicionales que las facilita. Contra un juego de lenguaje determinado no hay razón (lógica) que valga a no ser que esa razón se conciba como persuasividad. En este sentido los juegos de lenguaje son unidades de persuasión que abren una determinada lógica: «El metafísico piensa que existe un abrumador deber intelectual de presentar argumentos para sostener las opiniones polémicas que uno tiene, argumentos que partirán de premisas relativamente fuera de discusión. El ironista piensa que tales argumentos —los argumentos lógicos— están perfectamente bien para sus propósitos y son útiles como artificios para la exposición, pero que en última instancia no son sino for-

Durante la creación de prácticas sociales bien definidas y razonablemente autónomas, como la ingeniería o la jurisprudencia, desarrollamos criterios en calidad de herramientas para regular esta práctica [...]. Pero el proyecto general de las sociedades libres - el proyecto de ocupar las perspectivas democráticas no es una práctica mejor definida que la de escribir o leer poemas o la de enamorarse—».

${ }_{64}^{64}$ Rorty, R., «Respuesta a Kolakowski», en NizniK, J. - SANDERS, J. T., (2000), p. 86: «Nosotros los pragmatistas no creemos que haya cosas tales como "criterios de utilidad". Lo único que existe es la práctica de tratar de ser felices de la mejor manera que podamos».

${ }_{65}$ Rorty, R., (1993), p. 144: «No sólo no existe un consenso universal sobre las condiciones de inteligibilidad o los criterios de racionalidad, sino que nadie pretende siquiera que los haya, excepto como recurso retórico ocasional y bastante poco eficaz».

${ }_{66}$ RoRTy, R., (1996b), p. 296.

${ }_{67}$ La clave está en mantener la racionalidad, pese a rechazar la verdad substantiva, aunque desde el racionalismo se le tilde de «irracionalista», reproche que asumiría si el precio es ejercer la fuerza de la verdad, esa que tan a menudo se ha impuesto a golpes. Así, dice Rorty en "La emancipación de la cultura», en NizNIK, J. - SANDERS, J. T., (2000), p. 46: «Me gustaría que separáramos la noción de racionalidad de la de verdad. Quisiera definir la racionalidad como el hábito de lograr nuestros fines por medio de la persuasión y no por la fuerza. Tal como lo veo, la oposición entre racionalidad e irracionalidad no es ni más ni menos que la oposición entre palabras y golpes».

${ }_{68}$ RoRTY, R., (1985), p. 463.

69 Rorty, R., «El desafío del relativismo», en NiznIK, J. - SANDERS, J. T., (2000), p. 53: «Nuestros esfuerzos de persuasión deben adoptar la forma de progresiva penetración de una nueva manera de hablar y no de una argumentación directa en el interior de viejas maneras de hablar». 
mas de hacer que las personas modifiquen sus prácticas sin admitir que lo han hecho. La forma de argumentación preferida del ironista es dialéctica en el sentido de que considera que la unidad de persuasión es el léxico antes que la proposición. Su método es la redescripción y no la inferencia [...]. Así pues, el ironista piensa que la lógica mantiene una relación auxiliar con la dialéctica, mientras que el metafísico piensa que la dialéctica es una especie de retórica, la cual es a su vez un falso sustituto de la lógica» ${ }^{70}$.

Creemos que en el párrafo citado, como en general en la obra rortiana, «ironista» y «metafísico» son sustituibles respectivamente por «hombre retórico» $\mathrm{y}$ «hombre serio». $\mathrm{Y}$ al igual que $\mathrm{S}$. Fish mostraba que el último es una especie del primero, aunque la más aburrida — podríamos añadir - Rorty vendría a decir también que el metafísico, el filósofo tradicional, fundacionalista y representacionalista, es un ironista malgré lui. Y, por consiguiente, un retórico sin saberlo. Si la analogía es válida, entonces la retórica no es lo otro de la filosofía heliotrópica; antes al contrario, la filosofía es otra retórica, aunque sea la retórica de la antirretórica, una retórica que camufla su intención de conseguir la adhesión de su auditorio, de persuadirlo para que modifique sus prácticas. Lo que irónicamente nos viene a enseñar entonces Rorty es que, al contraponer filosofía y retórica, de hecho, estamos contraponiendo dos retóricas, distintas sí, pero retóricas. Luego la contraposición se mueve en el seno de la misma retórica ${ }^{71}$.

\section{VII}

Ahora bien, señalado el género próximo, podemos identificar la diferencia específica de la retórica rortiana. Como ha indicado J. S. Horne ${ }^{72}$, Rorty tiene dos estrategias retóricas predilectas, a saber, la «redescripción» y la "conversación». Toquemos la primera, el «método» del ironista. "Los ironistas se especializan en redescribir grupos de objetos o de acontecimientos en una jerga formada en parte por neologismos, con la esperanza de incitar a la gente a que adopte y extienda esa jerga. Un ironista piensa que cuando haya dejado de utilizar las viejas palabras con un nuevo sentido - y, por supuesto, cuando haya dejado de introducir palabras enteramente nuevas- la gente ya no planteará preguntas formuladas con los viejos términos» ${ }^{73}$. La redescripción es el discurso "anormal», fuera de los cánones aceptados (de la lógica de La Única Descripción Adecuada), que los ironiza exhibiendo su no necesidad, su carácter contingente y opcional, su carácter «retórico» que diríamos nosotros, ampliando así los límites de la posibilidad. Mediante la redescripción, la filosofía se puede hacer «edificante» (en lugar de "sistemática») ${ }^{74}$ y verse como

70 Rorty, R., (1991), p. 96.

${ }^{71}$ De ahí el papel prevalente de la persuasión, de la argumentación persuasiva sobre la argumentación lógica, también en el plano ético y político, plano a veces aludido aquí, pero que, por razones de espacio, postergamos deliberadamente para otro trabajo, no sin señalar ya, sin embargo, que ese papel lo lleva Rorty a la hipérbole al imaginar su «utopía liberal», una sociedad poblada por liberales (enemigos acérrimos de la violencia, la tortura y la crueldad) ironistas (conscientes de la contingencia o no necesidad de su léxico último). Valga, como botón de muestra, RoRTY, R., (1991), p. 70: «Esa sería precisamente la forma de sociedad que los liberales intentan evitar: una sociedad en la que imperase la "lógica" y la "retórica" estuviese fuera de la ley».

${ }_{72}$ Cf. Horne, J. S., (1993), pp. 171-176. CALDER, G., (2003), p. 19, identifica «la típica estrategia retórica de Rorty», ya anotada, con la redescripción.

73 RoRTY, R., (1991), p. 96.

${ }^{74}$ Sobre la distinción entre filosofía «sistemática» y filosofía «edificante», véase RoRTY, R., (1989), pp. 330-336. 
un ejercicio de autonomía intelectual, ajeno a la busca de soluciones para los problemas tradicionales y expresión, en su lugar, de la idea romántica del humano como creador de sí mismo y de su lenguaje, como una práctica de filosofía-propuesta de futuro (en contraste con la filosofía-descubrimiento), toda vez que se abre una perspectiva ilimitada, ya que cualquier cosa puede ser objeto del discurso anormal tanto como puede ser sistematizada. La redescripción está así al servicio de la continua autocreación de nosotros mismos, a través de la invención de nuevos léxicos que, lejos de creer que nos acerquen mejor a La Realidad, nos resultan más útiles para crear nuevos y más interesantes mundos ${ }^{75}$.

La redescripción es propia de los filósofos «holistas», sabedores de que las palabras toman sus significados a partir de otras palabras más que en virtud de su carácter representativo, de que los vocabularios adquieren sus privilegios a partir del uso que se les da más que de su transparencia de lo real. Y de pragmatistas, intérpretes de la meta de toda investigación como la consecución de una mezcla apropiada de acuerdo no forzado y desacuerdo tolerante, de la racionalidad como algo «sensato» o "razonable» antes que «epistémico», pues decir de algo que es racional ahora y para nosotros no es creer que sea verdadero, sino que alguien puede venir con una mejor idea. La redescripción como «"método" de la filosofía es igual al "método" de la política utópica o de la ciencia revolucionaria (como opuestas a la política parlamentaria o a la ciencia normal). El método consiste en volver a describir muchas cosas de una manera nueva hasta que se logra crear una pauta de conducta lingüística que la generación en ciernes se siente tentada a adoptar, haciéndoles así buscar nuevas formas de conducta no lingüística [...]. Este tipo de filosofía no trabaja pieza a pieza, analizando concepto tras concepto, o sometiendo a prueba una tesis tras otra. Trabaja holista y pragmáticamente. Dice cosas como: "Intenta pensar de este modo", o, más específicamente, "Intenta ignorar las cuestiones tradicionales, manifiestamente fútiles, sustituyéndolas por las siguientes cuestiones, nuevas y posiblemente interesantes". No pretende disponer de un candidato más apto para efectuar las mismas viejas cosas que hacíamos al hablar a la antigua usanza. Sugiere, en cambio, que podríamos proponernos dejar de hacer esas cosas y hacer otras. Pero no argumenta a favor de esa sugerencia sobre la base de los criterios precedentes comunes al viejo y al nuevo juego del lenguaje. Pues en la medida en que el nuevo lenguaje sea realmente nuevo, no habrá tales criterios» ${ }^{76}$.

Semejante pronunciamiento es toda una declaración de «principios» de (filosofía) retórica, aunque Rorty no lo diga así. Él prefiere hablar de un «giro global en contra de la teoría y hacia la literatura» ${ }^{77}$. Pero lo cierto es que cuando ilustra ese giro de la manera más explícita, en «Philosophy without Principles», identifica la «teoría» (por cierto, en el sentido de visión libre de contexto que tiene en S. Fish) con un tipo de retórica y aboga por la no distinción (otra vez aparece el tópico de la distinción como distracción) entre filosofía y retórica: «Lo que es erróneo en esta cuestión [¿cómo sabes?] es que, como era preguntada por Sócrates y la tradición platónica, presupone que nosotros sabemos qué es el conocimiento y que podemos decir cuándo lo tenemos. Pero esta noción del conocimiento como estado introspectivo es precisamente otro mito platónico más. El modo correcto de plantear esa cuestión es “¿Por qué encuentras persuasivo lo que acabas de decir?”. Ésta es una cuestión que hace caso omiso de las tradicionales distinciones entre razones y causas, psicología y lógica, retórica y demostración. Es un cuestión práctica, una versión cortés de la cuestión “¿Qué voy a tener que hacer para convencerte?” ${ }^{78}$. Se

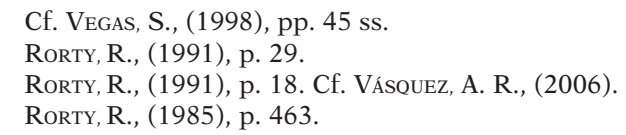


trata, así pues, y ésta es una cantilena frecuente en sus obras, no de cambiar filosofía por retórica, sino — «abandono de la ficción heurística de un público universal o un público ideal» ${ }^{79}$ mediante- de "cambiar de retórica», pues «nunca vamos a encontrar un argumento definitivo, e igual de eficaz con todos los auditorios [...], un argumento puramente "lógico" y en nada "retórico" ${ }^{80}$. Todo en filosofía queda dentro de la retórica, en la filosofía, al menos, de Rorty. Y es que «la retórica importa, especialmente si uno entiende la tradición pragmatista, como es mi caso, no meramente como un deshacer pequeños entuertos que dejaron tras de sí los grandes filósofos muertos, sino como una contribución a un cambio, de dimensión histórica mundial, en la autoimagen de la humanidad» ${ }^{81}$.

Y para cambiar de retórica, la segunda estrategia que emplea es la conversación, una de las funciones originarias de la retórica y la forma más eminente de ser humano, la más humana. En la constante preferencia rortiana por la conversación frente a la objetividad como meta de toda investigación ${ }^{82}$ vibra el clangor de la centralidad retórica de la filosofía en Rorty. Y es que centrarse en la conversación es otro modo de reafirmar la dialéctica, parte adjunta de la retórica y justo marcada por él como forma favorita de argumentación del ironista. Desde que en su primera obra mayor la tematizara y le dedicase el epígrafe «La filosofía y la conversación de la humanidad», siempre ha mantenido el ideal conversacional exhibiéndolo recurrentemente, que no es otro que el ideal hermenéutico, en contraste con el epistemológico, interpretativo «de la cultura como una conversación más que como una estructura levantada sobre unos fundamentos ${ }^{83}$. La prescindencia de fundamentos será deno(s)tada por el filósofo epistémico como retórica. Y, connotaciones aparte, llevará razón, pues no cabe duda de que la opción conversacional es punto álgido de la confrontación entre (la retórica de) la filosofía (fundacionalista) y la retórica (filosófica), ya que persigue «eliminar completamente de la conversación las metáforas visuales, y en especial la del espejo. Para hacerlo hemos de entender el habla no sólo como no exteriorización de las representaciones, sino como no representación en absoluto. Debemos renunciar a la idea de correspondencia de las oraciones y de pensamientos como si estuvieran conectadas con otras oraciones más que con el mundo» ${ }^{84}$. Nótese aquí la ausencia de un primer analogado, de un referente último extralingüístico, de un fundamento, la presencia exclusiva de palabras.

\footnotetext{
79 Rorty, R., «La noción de racionalidad», en Niznik, J. - SANDERS, J. T., (2000), p. 115. En esta página exhibe también su consecuente rechazo de la noción de «mejor argumento» y se oye el motto de la desvinculación de la racionalidad respecto de la verdad y su vinculación «a nociones como curiosidad, persuasión y tolerancia». Sobre la no existencia de una virtud llamada «racionalidad» distinta de esa virtudes morales, véase RorTy, R., (1996b), p. 62.

${ }^{80}$ Rorty, R., (2000b), p. 312. Ya Rorty, R., (1993), p. 136, manifiesta que «los argumentos sólo funcionan si el hablante y su auditorio comparten un vocabulario en el cual establecer sus premisas». Otra muestra de respeto rortiano a la regla de oro de la retórica, adaptar el discurso al auditorio, la encontramos en la respuesta dada al profesor Szahaj recogida en NizNIK, J. - SANDERS, J. T., (2000), p. 150: «Un pragmatista debe adaptar sus palabras a su público». O también en RoRTY, R., (2002), p. 14: «La justificación siempre es relativa a un auditorio»; de ahí su suspicacia ante la distinción entre verdad y justificación o entre validez genuina y manipulación retórica, pues la diferencia entre una cosa y otra se reduce a la diferencia entre viejos y nuevos auditorios; la más interesante explicación sobre este contraste de auditorios se encuentra en RoRTY, R., (2000a), pp. 88 ss.

${ }^{81}$ RoRTy, R., (2000b), p. 175.

${ }_{82}$ Rorty, R., (1989), p. 340: «El interés de la filosofía edificante es hacer que siga la conversación más que encontrar la verdad objetiva».

83 Rorty, R., (1989), p. 291.

${ }^{84}$ RoRTy, R., (1989), pp. 335-336.
} 
Y no sólo al habla apela Rorty, también al sentido del ridículo, al buen gusto, al tacto, a la prudencia o sabiduría práctica a la hora de caracterizar la conversación, en contraste con la opción epistémica, como la opción de los que él llama «filósofos edificantes» (como opuestos a los «sistemáticos»), es decir, a facultades que la (retórica de la) filosofía vítrea rechazaba como propias de la retórica. Y su ironismo no es irenismo, casi como un sofista de la antigüedad dice de los filósofos que él concibe como interlocutores en una conversación lo siguiente: «Los filósofos edificantes no pueden terminar la filosofía, pero pueden ayudar a impedir que llegue al sendero seguro de la ciencia» ${ }^{85}$. Su gran virtud es que señalan el camino hacia «una clase no epistemológica de filosofía y que, por tanto, renuncian a toda esperanza de lo "trascendental' ${ }^{86}$. Frente a esa esperanza bastaría la conformidad retórica de considerar que mantener una conversación es una meta suficiente de la filosofía, de hacer consistir la sabiduría en la capacidad de mantener una conversación. Pero no hay peligro de que la filosofía llegue a su fin; al menos, seguirán siendo necesarios los profesores que hayan leído a los grandes filósofos desaparecidos al servicio de que se mantenga la conversación de Occidente ${ }^{87}$.

\section{VIII}

Ahora bien, lo relevante de esa conversación occidental, donde Rorty ve el interés moral del filósofo, no es la mímesis del pasado, sino la poíesis del futuro. Lo que interesa a la filosofía rortiana no es la repetición de viejos esquemas dentro de la conversación sino ampliarla y expandirla con vistas a la creación de nuevos vocabularios alternativos a los de la tradición. Y el medio para ese fin no es argumentar contra la tradición (en el sentido de demostrar), sino poner a un lado, o dicho de manera más dura, minar la tradición. Se trata de olvidar las viejas malas cuestiones. Y eso exige, antes que argumentar, circunvalar la noción de argumento. La estrategia rortiana no va a consistir en ofrecer una argumentación alternativa, sino más bien en ofrecer una alternativa a la argumentación misma ${ }^{88}$. Es lo que se tematiza explícitamente en «Desconstrucción y circunvención» ${ }^{89}$. Y ahí el papel clave lo viene a desempeñar precisamente aquello a lo que (la tradicional retórica de) la filosofía había reducido la aportación de la retórica, a saber, a un puñado de tropos y figuras. Y si resulta que es justo la retórica restreinte ${ }^{90}$ - por utilizar la famosa calificación de G. Genette-, la tropología, aquello de lo que se va a valer principalmente

85 Rorty, R., (1989), p. 336.

86 RoRty, R., (1989), p. 344.

87 Cf. Rorty, R., (1989), pp. 354-355. Por eso, al menos en el caso rortiano, antes que hablar de que «la filosofía ha muerto para que pudiese nacer la retórica», como hace ScHRAG, C. O., (1985), p. 166, habría que hablar, aplicando el título del artículo de SutTon, J., (1986), de «la muerte de la retórica y su renacimiento en la filosofía».

${ }_{88}$ No se trata ya de que Rorty intente minar la tradición con sus «habilidades analíticas y retóricas» - como interpreta el acerbo crítico de la «retórica» rortiana, de su magistral dominio de los tropos retóricos, Berstein, R. J., (1992), p. 258; véase asimismo pp. 261 ss.- de que Rorty emplee un procedimiento capcioso contra el argumento, sino, antes al contrario, de no dar por sentado que podamos separar el procedimiento del argumento. Es decir, no es que Rorty se valga de la retórica para oponerse al argumento (por carecer de buenos argumentos), más bien viene a enseñar que no se pueden oponer, toda vez que no habría argumento sin retórica y especialmente sin previa incardinación trópica, lo que impide tomar una descripción opcional por la única descripción, la descripción necesaria.

${ }^{89}$ Cf. RoRTY, R. (1993), pp. 125-152.

90 Cf. Genette, G., (1970). 
Rorty a la hora de ofrecer su alternativa a la argumentación, entonces más inequívocamente que nunca se podrá hablar de la centralidad retórica de la filosofía rortiana ${ }^{91}$.

En efecto, ese «modelo» de racionalidad por el que Rorty apuesta («deberíamos contentarnos con la segunda concepción de la racionalidad, más débil») ${ }^{92}$, basado en el deseo de "sustituir la idea de "acuerdo no forzado" por la de "objetividad" ${ }^{93}$, «en favor de la retórica reformista sobre una mayor tolerancia y un menor sufrimiento» ${ }^{94}$, capaz de "alcanzar un acuerdo utilizando la persuasión antes que la fuerza» ${ }^{95}$, basado en «un conjunto de virtudes morales: tolerancia, respeto a las opiniones de quienes nos rodean, disposición a escuchar, recurso a la persuasión antes que a la fuerza» ${ }^{96}$, para el que «ser racional es simplemente examinar cualquier tema —religioso, literario, científico- de un modo que descarte el dogmatismo, la actitud defensiva y la radical indignación» ${ }^{97}$, es un modelo de racionalidad que, además de tener visos de satisfacer los clásicos criterios que lo definirían como retórico, tiene como núcleo cordial al propio corazón de la retórica: la tropología. Y no puede ser menos cuando se traspasa la frontera entre lo literal y lo metafórico, entre lo filosófico y lo literario.

Tal vez se entienda mejor este planteamiento transgresor de Rorty si se repara en el rol de la metáfora en Occidente. Ésta tradicionalmente se ha concebido como «metáfora restringida», como un elemento de adorno, algo decorativo, nunca substantivo, mera cuestión de palabras, nunca de pensamiento. Esto era algo que implícita o incluso explícitamente asumían las poéticas clásicas. Lo metafórico se sobreponía a lo conceptual para restarle sequedad y dureza, pero sin penetrar jamás en su núcleo. Toda metáfora, en último término, podía ser traducida a concepto. Es más, pasada la eventual emoción estética, lo valioso de lo literario era su filtrado racional, su destilado literal. La noción de metáfora ha girado efectivamente en torno a la noción de «sustitución», mera figura (forma sin contenido), algo o no significativo o de significación vicaria que alcanza su pleno significado cuando es reemplazado por su concepto propio, cuando se decanta su referente real. Esta interpretación clásica de la metáfora es posible sólo si concebimos la semántica como aparte de la sintaxis y de la pragmática, si presuponemos el espejo metafísico, o sea, si se parte impremeditadamente de que los significados son objetivos, de que son objetos recibidos en las expresiones lingüísticas, las cuales son así pasivos recipientes, recipientes para los activos significados. Pero éstas son las presuposiciones de la filosofía-espejo que Rorty rechaza fehacientemente. Él hace borrosa la distinción entre lo literal y lo metafórico, porque nos viene a decir que vivimos mediante metáforas, es decir, que nuestro pensamiento está estructurado metafóricamente, que no hay experiencia humana al margen de las metáforas. Y que, por tanto, las metáforas están a la base de cualquier operación de significado, de toda comprensión. Creer que hay un referente (realidad, naturaleza, unidad, literalidad, concepto, lógica) independiente de nuestras experiencias al que podemos acceder en toda su pureza es justo una creencia, no algo demostrable conceptualmente, aceptable universalmente, natural, real, lógico.

\footnotetext{
${ }_{91}$ Aunque va de suyo que se trata ahora de una tropología no restringida ya a la mera clasificación de tropos y figuras, sino al impacto y efectividad de la imaginación creativa expresada por los tropos. Véase HoRne, J. S., (1993), p. 180, n. 11.

92 Rorty, R., (1996b), p. 60.

Rorty, R., (1996b), p. 61.

Rorty, R., (1996b), p. 288.

Rorty, R., (1996b), p. 125.

Rorty, R., (1996b), p. 59.

${ }_{97}$ Rorty, R., (1996b), p. 59.
} 
De nuevo hay que recalcar que esto no significa negar una «realidad» exterior, un out there, sino, antes al contrario, negar que nosotros seamos exteriores a la realidad: suponemos que hay cosas y que las cosas causan la experiencia. En esto, valga la ironía, hay que ser «objetivista», lo que ocurre es que los objetos por sí solos no conforman «hechos»: «No hay forma de identificar un objeto más que hablando de él» ${ }^{98}$. Una cosa es la «realidad» bruta y otra los hechos brutos. Con éstos no podemos contar, pues no hay experiencia de hechos extralingüísticamente, toda vez que «hay tantos hechos que se incorporan al mundo como lenguajes para describir esa transacción causal» ${ }^{99}$. Y a la base de los lenguajes están las metáforas: no hay lenguaje que no dependa de metáforas, de semejanzas ya no objetivas, inherentes a las cosas, sino traslaticias, es decir, basadas en otras metáforas o conceptos metafóricos. Y esto no se puede argumentar demostrativa o lógicamente. Rorty se justifica metafóricamente ${ }^{100}$. Ahora bien, no sin destacar retorsivamente que la perspectiva que separa lo metafórico de lo literal no es menos metafórica ${ }^{101}$.

\section{IX}

Lo que está en juego no son los argumentos, la lógica, sino las metáforas, la «tropológica». Ciertamente, Rorty en su obra más que proponer argumentos nuevos compartiendo la lógica con que argumentar, otro contenido dentro de una forma común, está proponiendo un cambio en la «forma» del pensar, una nueva «lógica» (aunque su novedad reside precisamente en no aceptar de antemano el dualismo contenido/forma). Lo relevante no es tanto innovar los argumentos dentro de la matriz tradicional como cambiar la matriz en cuyo seno argumentar. Por tanto, no se trata de que pretenda haber encontrado, por fin, argumentos verdaderos, en virtud de los cuales los otros argumentos se muestren como falsos, sino de sustraerse a la lógica universal en virtud de la cual los argumentos, fuera de contexto, son verdaderos o falsos. Eso es lo que significan estribillos trópicos típicamente rortianos como "poner a un lado», «minar» la tradición, «abandonar las viejas malas controversias». Esta operación no es lógica, sino retórica. Y ya

98 RoRTy, R., (1996b), p. 125.

99 RoRTy, R., (1996b), p. 117. Los «hechos» para nuestro autor vienen a ser una construcción retórica; así interpretamos que en la página anterior a la citada conciba «la reputada dureza de los hechos de la ciencia como un artificio creado por nuestra elección del juego de lenguaje».

100 En la línea precisamente de los filósofos edificantes, frente a los «grandes filósofos sistemáticos [, que] son constructivos y dan argumentos» —RoRTY, R., (1989), p. 354.

101 RoRTy, R., (1996b), pp. 117-118: «La tradición filosófica ha ansiado encontrar una forma de aproximarse a la total pasividad de la hoja en blanco. Ha concebido el lenguaje como un ente interpuesto, como un cojín entre nosotros y el mundo. Ha lamentado que la diversidad de los juegos del lenguaje, de las comunidades interpretativas, nos permita tanta variación en la manera de responder a las presiones causales. Le gustaría que fuésemos máquinas de producir enunciados verdaderos en respuesta "directa" a la presión de la realidad sobre nuestros órganos. En cambio, los pragmatistas consideran que la metáfora del lenguaje como cojín del efecto de las fuerzas causales ya no puede explotarse con provecho. [...] Las metáforas que, según el pragmatista, ponemos en lugar de toda esa referencia masoquista al carácter duro y directo son las de la conducta lingüística como uso de herramientas, del lenguaje como una manera de asir las fuerzas causales y conseguir que hagamos lo que deseamos, modificarnos a nosotros y a nuestro entorno según nuestras aspiraciones. El pragmatista exalta así la espontaneidad al precio de la receptividad. Igual que su adversario realista hizo lo contrario. [...] Pero el pragmatista no intenta justificar sus metáforas mediante un argumento filosófico [...], cuenta relatos sobre cómo se ha idiotizado el decurso del pensamiento occidental por obra de las metáforas que detesta». Esta preferencia por las metáforas de espontaneidad va ligada a la de metáforas de expansión y, en general, a la «profecía romántica» como el «tipo de retórica» que «debería emplear un pragmatista»; al respecto, véase la respuesta dada al profesor Szahaj recogida en NiznIK, J. - SANDERS, J. T., (2000), p. 152. 
dentro de la retórica es un movimiento tropológico, toda vez que es la metáfora la que activa esa operación. Nuestro autor no está diciendo que la tradición sea falsa y argumentado veritativamente esa falsedad, sino que viene a mostrar que la tradición viene de un parti pris obediente a una metáfora. Sólo a partir de la aceptación previa de esa metáfora tendría sentido hablar de lo verdadero o falso de los argumentos enunciados en la tradición histórica. Pero Rorty — digámoslo así- lo que viene a hacer es negar la premisa mayor que subtiende a la tradición, vista ahora como una petitio principii inaceptable. Por eso en lugar de «argumentar» contra la tradición, lo que hace es proponer una nueva metafórica, las metáforas de la espontaneidad creativa y de expansión, en lugar de las metáforas de la pasividad receptiva y de profundidad ${ }^{102}$.

Ahora bien, lo que nos interesa ahora no son las diversas metáforas de Rorty, sino hablar, aun cuando parcial y brevemente, de la metáfora en Rorty, de su papel clave. En efecto, la metáfora ejecuta un rol central para comprender tanto lo que el lenguaje no es como, sobre todo, para acercarnos a lo que el lenguaje «es»: una herramienta conveniente. Ya hemos examinado que el lenguaje no es representación, que entenderlo así es hacerlo dependiente de la metáfora del espejo, una metáfora invisible que Rorty nos hace ver. Se trata ahora de acercarnos ahora a la metáfora como llave con la que la filosofía rortiana abre la puerta de acceso a la cuestión del significado, o mejor, a la de la producción de significados. Y es que el valor de la metáfora reside en su ampliación del campo de la posibilidad: las posibilidades no están todas dadas a la mano con eterna antelación desde la noche de los tiempos, sino que las posibilidades hay que crearlas, siendo la metáfora el vehículo privilegiado de esa creación, «el punto de crecimiento del lenguaje» ${ }^{103}$.

En efecto, Rorty parte de un sedicente «dogma», a saber, que el tejido o red de nuestras creencias y deseos se reteje añadiendo una nueva creencia a las previas, y ello se lleva a cabo mediante dos medios que, por analogía con otros usos rortianos de la denominación «normal», podemos llamar «normales» (normales porque son tanto los habituales como los que tienen valor de norma, según prescribe la tradición) o conservadores del lenguaje y del mundo lingüísticamente constituido (conservadores porque los dejan intactos), y otro medio que, por la misma analogía, podemos llamar «anormal». Esos dos medios normales son la percepción y la inferencia. El medio no normal es la metáfora. La percepción añade una nueva creencia en la red de las anteriores. La inferencia cambia nuestras creencias haciéndonos ver que hemos de modificar las viejas o revisar las consecuencias de la nueva, pues nos hace ver que nuestras anteriores creencias nos comprometen con una creencia que no habíamos tenido anteriormente. La tradición antirretórica sólo venía a admitir percepciones e inferencias como únicos medios de hacer cambiar nuestras creencias, con lo cual sólo podía aceptarse el cambio del valor de verdad de las oraciones, pero no del repertorio conjunto de las oraciones. O sea, el lenguaje, el modo de descomponer el campo de la posibilidad, quedaba intacto. Y eso era «suponer que el lenguaje que hablamos actualmente es, por así decirlo, todo el lenguaje existente, todo el lenguaje que podemos necesitar» ${ }^{104}$. O dicho de otra manera, era suponer, como ha hecho esa tra-

${ }_{102}$ Sin embargo, hay quien ha señalado que, por así decir, en Rorty predomina más la pars destruens que la construens, que destaca más en él lo que rechaza que lo que propone. Un crítico de este tipo es ABRAMs, J. J., (2002), quien considera que Rorty podría haber prestado más atención, a la hora de proponer una alternativa a la metáfora de la mente como espejo, a James y Whitehead y, sobre todo a Peirce, quien desarrolló una específica concepción de la mente y el mundo anticartesiana, antifundacionalista y semiótica, como algo «fluido».

${ }_{103}$ RoRTy, R., (1993), p. 28. Precisamente en Arist. Rhet. I, 2, 1357a se liga la retórica no a la necesidad sino a la posibilidad, como el arte de aconsejar sobre las cosas que podrían ser así o también de otra manera.

104 RoRTY, R., (1993), p. 29. 
dición, que la lógica no es histórica, que cambian los contenidos, mas la forma lógica permanece, que conocer es reconocer, que adquirir la verdad es cuestión de encajar datos en un esquema preestablecido, de hacer explícito un núcleo de posibilidades permanente y neutro. «Por el contrario, considerar la metáfora como una tercera fuente de creencias, y por tanto como un tercer motivo para rehacer nuestra red de creencias y deseos, es considerar el lenguaje, el espacio lógico y el ámbito de la posibilidad como algo abierto» ${ }^{105}$.

Retumba ahí la oposición de Rorty a la pretensión filosófica de lograr el grado cero de retórica, el desenmascaramiento de su rostro retórico como retórica que se presenta exenta de retórica. Nuestro autor retuerce esa posición antirretórica y presenta como sueño nuclear de la filosofía literal el aislar la metáfora central al corazón del lenguaje: «Decir que los filósofos sueñan con que sólo exista una verdadera metáfora es decir que sueñan con [...] mostrar que en realidad sólo existe un lenguaje y que todos los demás (pseudo)lenguajes carecen de alguna propiedad para ser "significativo", "inteligible", “completo" o "adecuado" » ${ }^{106}$. Frente al sueño del lenguaje único, lenguaje perfecto, que nos transparenta la cosa, considera el hablar varios lenguajes como seña distintiva o divisa de los pensadores importantes, revolucionarios y originales, por lo que se ganan la acusación «de introducir extraños sentidos nuevos a expresiones conocidas, de juguetear frívolamente, de no seguir las reglas, de utilizar la retórica en vez de la lógica, la imaginación en vez de la argumentación ${ }^{107}$. No puede desoírse aquí la centralidad de la retórica, más en particular, de la tropología en la filosofía de Rorty: desechado el diapasón del único lenguaje «natural», el lenguaje, la lógica, se hace plural, y a la base inaugural de esa pluralidad se encuentran los «ruidos poco familiares» ${ }^{108}$, las metáforas.

105 RoRTy, R., (1993), p. 29.

106 RoRTy, R., (1993), p. 130.

107 RoRTY, R., (1993), pp. 142-143 («Están forjando nuevas formas de hablar, y no realizando sorprendentes descubrimientos filosóficos sobre obras antiguas. En consecuencia, no es probable que su argumentación sea buena», p. 136). Esta acusación debe ser relacionada con la postura rortiana sobre la intraducibilidad de las metáforas (no hay «teoría» de las metáforas), pues ellas se distinguen de los conceptos no por su significado (los conceptos son metáforas muertas, ya literalizadas) sino por su uso — cf. RoRTY, R., (1991), pp. 37 ss.- y con la consideración obsecuente en RoRTY, R., (1996b), p. 236, según la cual «preguntar “¿cómo funcionan las metáforas?” es como preguntar cómo opera el genio. Si lo supiésemos, el genio sería superfluo». Y sobre el genio, véase también RoRTY, R., (1991), pp. 49 ss., y RoRTY, R., (1993), p. 31. La genialidad — aquí topamos con la inventio retórica y tal vez con la illusio aristotélica — viene a consistir en la contingente facultad fantástica o imaginativa de crear metáforas, las cuales, aun cuando causadas por algo previamente existente, no expresan nada previamente existente. Por eso el héroe rortiano, paradigma de la humanidad, no es el contemplador, sino el creador de metáforas, el poeta vigoroso, y la historia de la ciencia (y de la cultura) lo es, antes que de los descubrimientos, de las metáforas — cf. RoRTY, R., (1991), p. 40.

108 Cf. «Ruidos poco conocidos» en RoRTY, R., (1996b), pp. 223-236. Al respecto, véase la acusación a Rorty (y a Hesse) de GAL, O., (1995), pp. 142 ss., por no ser «suficientemente radical para asignar un rol filosófico positivo a la retórica»: la retórica sólo podrá ser un elemento constitutivo de su filosofía cuando se admita que la «red de significados» se teje mediante relaciones trópicas, sólo así se daría cuenta no sólo del cambio de significado, sino del significado mismo. Pero aquí lo que defendemos es el «colapso" de retórica y filosofía en Rorty, que ambas convertuntur en un horizonte común, no que unilateralmente la una se convierta en la otra; no obstante, puestos a distinguir, no tratamos tanto de que Rorty asigne un rol filosófico positivo (epistemológico) a la retórica, sino más bien de que implícitamente está asignado un rol retórico positivo a la filosofía. Es decir, más que «elevar» la (horizontal, superficial) retórica a filosofía, Rorty está «rebajando» la presuntamente alta (vertical, profunda) filosofía a retórica, una retórica así desconectada de la epistemología y reconectada a la tropología, exonerada del «ostracismo platónico». O como dice —dándole de hecho la vuelta a la Rhetoric as Epistemic de R. L. Scott-Horne, J. S., (1989), p. 287: «La retórica después de Rorty puede que ya no sea confortablemente epistémica, la epistemología puede que se haya hecho retórica». Y es que, según RoRTY, R., (1989), p. 290: «Ser racional es estar dispuesto a abstenerse de la epistemología [...] y estar dispuestos a adquirir la jerga del interlocutor en vez de traducirla a la suya propia». Racionalidad y retórica, lejos de repelerse, al quedar redescritas, convergen. 
En efecto, si sólo hubiese un lenguaje, éste sería fijo y estable, estaría dado del todo, con un orden transcendental, su malla a priori se rellenaría mediante la intuición empírica o racional, con lo que la metáfora quedaría devaluada a ornato, todo el valor racional residiría en el argumento lógico. Pero Rorty está haciendo funcional la racionalidad a la metáfora, pues ella escapa al argumento. El argumento extiende su validez a partir de la intangibilidad del lenguaje. Y justo la metáfora acaba con esa intangibilidad como son ampliador de la posibilidad y con ello extiende los límites del mundo, en tanto que precursora de nuevos juegos del lenguaje que arrumban a los antiguos. Su papel es crucial: «La metáfora es, por así decirlo, una voz desde fuera del espacio lógico, en vez de un rellenado empírico de una parte de ese espacio, o una clarificación lógico-filosófica de la estructura de ese espacio. Es una llamada a cambiar el propio lenguaje y la propia vida, en vez de una propuesta de sistematización de ambos» ${ }^{109}$.

Así, el «más largo error» aparece, a su vez, como metáfora, el discurso filosófico de la tradición no es menos metafórico que los discursos retóricos repudiados por «trópicos». Y es que, más allá de la filosofía, toda «nuestra cultura no sólo se ha elevado mediante un manantial burbujeante de juegos de palabras y metáforas; ha sido cada vez más consciente de no descansar sobre nada más sólido que semejante géiser» ${ }^{110}$. La opción ya no se da, en definitiva, entre filosofía y retórica, sino entre tipos de retórica filosófica, toda vez que los problemas filosóficos quedan reducidos a tropos, «sólo como algunos tropos más» ${ }^{111}$, tropos que los argumentos "parasitan» ${ }^{112}$ : la invención de argumentos requiere antes de la invención, siempre trópica, de nuevos lenguajes. La filosofía es un tipo de retórica. Al menos, la rortiana. Y sus preguntas, a falta de argumentos, nunca dejaran de ser retóricas ${ }^{113}$.

\section{BiBLIOGRAFÍA}

ABrams, J. J. (2002): «Philosophy after the mirror of nature: Rorty, Dewey, and Peirce on pragmatism and metaphor», Metaphor and Symbol, 17/3, pp. 227-242.

ÁlLVAREz, A. (2000): «Biología como antidualismo», A parte Rei, 20, pp. 1-30 [online]. Disponible en Internet: http://serbal.pntic.mec.es/ cmunoz11/asunrorty.pdf. Archivo capturado el 25 de enero de 2009.

BRAGUES, G. (2006): «Richard Rorty's postmodern case for liberal democracy: a critique», Humanitas, XIX/1-2, pp. 158-181.

Berstein, R. J. (1992): The new constellation. The ethical-political horizons of modernity/postmodernity, Cambridge (MA), MIT Press.

CARTER, K. - PRESnell, M. (1994): Interpretive approaches to interpersonal communication, Albany, State University of New York Press.

109 RoRTy, R., (1993), pp. 29-30. Repárese en el énfasis en lo oral, justo lo genuino inicialmente de lo retórico, que pone Rorty en esta caracterización (del valor) de la metáfora: «voz» y «llamada». Añádase a esto su adhesión a la preferencia heideggeriana por las «metáforas auditivas» en RoRTY, R., (1993), p. 32.

${ }_{110}$ RoRTY, R., (1993), p. 149.

111 RoRTy, R., (1993), p. 150. Se propone leer la bina (relativa al problema de la relación entre) filosofía y retórica al compás de estas palabras: «El intento de hallar un vocabulario cerrado y total produjo multitud de grandes oposiciones binarias, que a continuación poetas, ensayistas y novelistas pasaron a utilizar como tropos. Pero se puede muy bien utilizar un tropo sin tomar en serio su pretensión de formar parte de semejante vocabulario» (p. 152). Semejante vocabulario ya está «maduro» para su redescripción.

112 RoRTY, R., (1991), p. 29.

113 Rorty, R., (2000b), p. 61: «Al final, los pragmatistas carecemos de verdaderos argumentos [...]. Todo lo que tenemos son preguntas retóricas [...]. Pero preguntas retóricas como éstas han sido en el pasado instrumentos para el cambio sociocultural, y pueden volver a serlo». 
FISH, S. (1989): Doing what comes naturally. Change, Rhetoric and the practice of theory in Literary and Legal Studies, Oxford, Oxford University Press.

FRÖHLICH, S. (2008): «Rhetorik und Wissenschaft: Von einer rhetorischen Erkenntnistheorie zur Wissenschaftskritik der Social-Text-Affäre», Rhetorica, XXVI/4, pp. 439-453.

GAL, O. (1995): «Hesse and Rorty on metaphor: Rhetoric in Contemporary Philosophy», The Journal of Speculative Philosophy, 9/2, pp. 125-146.

GeERTZ, C. (1988): Works and lives. The anthropologist as author, Stanford, Stanford University Press.

Genette, G. (1970): «La rhétorique restreinte», Communication, 16, pp. 158-171.

Holmberg, C. (1977): «Dialectical Rhetoric and rhetorical Rhetoric», Philosophy and Rhetoric, 10, pp. 232-243.

Horne, J. S. (1989): «Rhetoric after Rorty», Western Journal of Speech and Communication, 53, pp. 247-259.

- (1993): «Circumvention of argument. Redescribing Rhetoric», The Southern Communication Journal, 58, pp. 169-181.

- (2001): «Truth or consequences: Pragmatism, Relativism, and Ethics», en PerRY, D. K. (ed.), American pragmatism and communication research, Mahwah, NJ, Lawrence Erlbaum, pp. 149-170.

JAY, M. (1994): Downcast Eyes. The denigration of vision in twentieth-century French thought, Berkeley, University of California Press.

Jonas, H. (1997): «Der Adel des Sehens, Eine Untersuchung zur Phänomenologie der Sinne», en Konersmann, R. «Kritik des Sehens», Reclam Verlag, Leipzig, pp. 246-271.

KISSEL, A. (2005): «Deliberative architectonic Rhetoric: a new method for resolving interdisciplinary conflicts» (A dissertation proposal submitted to the Committee on Social Thought, The University of Chicago, Accepted May 2003, Revised April 2005).

Langsdorf, L. - SMith, A. R. (eds.) (1995): Recovering pragmatism's voice. The classical tradition, Rorty, and the Philosophy of Communication, Albany, State University of New York Press.

LEFF, M. (1978): «In search of Ariadne's thread. A review of the recent literature on Rhetorical Theory», Central States Speech Journal, 29, pp. 73-91.

Lloyd, G. E. R. (1987): Polaridad y analogía. Dos tipos de argumentación en los albores del pensamiento griego, Madrid, Taurus.

Marín-Casanova, J. A. (1999): «The rhetorical centrality of Philosophy: from old Metaphysics to the New Rhetoric», Philosophy and Rhetoric, 32/2, pp. 160-174.

- (2011): «Arreglándoselas con la tradición: Rorty y los usos del legado filosófico», Contrastes. Revista Internacional de Filosofía, XVI/1-2, pp. 271-289.

Nelson, J. S. - Megill, A. (1986): «Rhetoric of inquiry: projects and prospects», Quarterly Journal of Speech, 72, pp. 20-37.

NizniK, J. - Sanders, J. T. (eds.) (2000): Debate sobre la situación de la filosofía. Habermas, Rorty y Kolakowski, Madrid, Cátedra.

Oesterreich, P. L. (2002): «Thesen zum homo rhetoricus und zur Neugestaltung der Philosophie im 21. Jahrhundert», Rhetorica, 4/3, pp. 289-298.

Parry, D. M. (1991): «The Aesthetic in Vico and Nietzsche», New Vico Studies, 9, pp. 29-42.

Perelman, Ch. (1989): Rhétoriques, Bruxelles, Editions de l'Université de Bruxelles.

Rorty, R. (1985): «Pragmatism and Literary Theory II. Philosophy without principles», Critical Inquiry, 11/3, pp. 459-465.

- (1989): La filosofía y el espejo de la naturaleza, Madrid, Cátedra.

- (1991): Contingencia, ironía y solidaridad, Barcelona, Paidós.

- (1993): Ensayos sobre Heidegger y otros pensadores contemporáneos. Escritos filosóficos 2, Barcelona, Paidós.

- (1996a): Consecuencias del pragmatismo, Madrid, Tecnos.

- (1996b): Objetividad, relativismo y verdad. Escritos filosóficos, Barcelona, Paidós.

- (1997): ¿Esperanza o conocimiento? Introducción al pragmatismo, Buenos Aires, FCE.

- (1998): Pragmatismo y política, Barcelona, Paidós.

- (1999): Forjar nuestro país. El pensamiento de izquierdas en los Estados Unidos del siglo XX, Barcelona, Paidós.

- (2000a): El pragmatismo, una versión. Antiautoritarismo en epistemología y ética, Barcelona, Ariel. 
- (2000b): Verdad y progreso. Escritos filosóficos, Barcelona, Paidós.

- (2002): Filosofía y futuro, Barcelona, Gedisa.

Simons, H. W. (1985): «Chronicle and critique of a conference», Quarterly Journal of Speech, 71/1, pp. 52-64.

Simons, H. W. (1990): «Preface», en Simons, H. W. (ed.), The rhetorical turn. Invention and persuasion in the conduct of inquiry, pp. vii-xii, Chicago, University of Chicago Press.

SchraG, C. O. (1985): «Rhetoric resituated at the end of Philosophy», Quarterly Journal of Speech, 71/1, pp. 164-174.

Sutton, J. (1986): «The death of Rhetoric and its rebirth in Philosophy», Rhetorica, XX/3, pp. 203226.

VÁsQuEZ, A. R. (2006): «Rorty: la realidad como narrativa exitosa y la filosofía como género literario", Límite. Revista de Filosofía y Psicología, 1/13, pp. 5-23.

Vegas, S. (1998): Richard Rorty, Madrid, Ediciones del Orto.

Universidad de Sevilla

José A. Marín-Casanova

jamarin@us.es

[Artículo aprobado para publicación en diciembre de 2011] 